\title{
Fenofibrate plus Metformin Produces Cardioprotection in a Type 2 Diabetes and Acute Myocardial Infarction Model
}

\author{
Víctor Hugo Oidor-Chan, ${ }^{1,2}$ Enrique Hong, ${ }^{1}$ Francisca Pérez-Severiano, ${ }^{3}$ \\ Sergio Montes, ${ }^{3}$ Juan Carlos Torres-Narváez, ${ }^{2}$ Leonardo del Valle-Mondragón, ${ }^{2}$ \\ Gustavo Pastelín-Hernández, ${ }^{2}$ and Alicia Sánchez-Mendoza ${ }^{2}$ \\ ${ }^{1}$ Department of Pharmacobiology, Research and Advanced Studies Center, National Polytechnic Institute (IPN), \\ Calzada de los Tenorios No. 235, Colonia Granjas Coapa, Tlalpan, 14330 Mexico City, Mexico \\ ${ }^{2}$ Department of Pharmacology, National Institute of Cardiology Ignacio Chávez, Juan Badiano No. 1, Colonia Sección XVI, \\ Tlalpan, 14080 Mexico City, Mexico \\ ${ }^{3}$ Department of Neurochemistry, National Institute of Neurology and Neurosurgery Manuel Velasco Suárez, \\ Insurgentes Sur No. 3877, Colonia La Fama, Tlalpan, 14269 Mexico City, Mexico \\ Correspondence should be addressed to Alicia Sánchez-Mendoza; masanchez@gmail.com
}

Received 7 January 2016; Accepted 18 February 2016

Academic Editor: Yanbo Fan

Copyright ( 2016 Víctor Hugo Oidor-Chan et al. This is an open access article distributed under the Creative Commons Attribution License, which permits unrestricted use, distribution, and reproduction in any medium, provided the original work is properly cited.

\begin{abstract}
We investigated whether fenofibrate, metformin, and their combination generate cardioprotection in a rat model of type 2 diabetes (T2D) and acute myocardial infarction (AMI). Streptozotocin-induced diabetic- (DB-) rats received 14 days of either vehicle, fenofibrate, metformin, or their combination and immediately after underwent myocardial ischemia/reperfusion (I/R). Fenofibrate plus metformin generated cardioprotection in a DBI/R model, reported as decreased coronary vascular resistance, compared to DBI/R-Vehicle, smaller infarct size, and increased cardiac work. The subchronic treatment with fenofibrate plus metformin increased, compared with DBI/R-Vehicle, total antioxidant capacity, manganese-dependent superoxide dismutase activity (MnSOD), guanosine triphosphate cyclohydrolase I (GTPCH-I) expression, tetrahydrobiopterin: dihydrobiopterin $\left(\mathrm{BH}_{4}: \mathrm{BH}_{2}\right)$ ratio, endothelial nitric oxide synthase (eNOS) activity, nitric oxide (NO) bioavailability, and decreased inducible NOS (iNOS) activity. These findings suggest that PPAR $\alpha$ activation by fenofibrate + metformin, at low doses, generates cardioprotection in a rat model of T2D and AMI and may represent a novel treatment strategy to limit I/R injury in patients with T2D.
\end{abstract}

\section{Introduction}

Type 2 diabetes (T2D) is a chronic metabolic disorder that results from defects in both insulin secretion and insulin action. Elevated rates of basal hepatic glucose production in the presence of hyperinsulinemia are the primary cause of fasting hyperglycemia; after a meal, impaired suppression of hepatic glucose production by insulin and decreased insulinmediated glucose uptake by muscle contribute almost equally to postprandial hyperglycemia [1]. Diabetic patients develop vascular complications at a much faster rate in comparison to nondiabetic individuals, and cardiovascular risk is increased up to tenfold [2]. It is estimated that more than $50 \%$ of diabetic patients die from a cardiovascular event, most likely coronary artery disease [3]. The development of cardiovascular disease in T2D is multifactorial; some mechanisms include glucose itself as well as glucose dependent mechanisms, such as the formation of advanced glycation endproducts (AGEs) [4], the activation of vasoactive hormonal systems, for example, the renin-angiotensin system (RAS) [5], and increased oxidative stress [4].

Under physiological conditions, in the vasculature, nitric oxide (NO) is produced mainly by endothelial nitric oxide synthase (eNOS), where it fulfills vasodilatory, antithrombotic, and antiatherosclerotic functions [6]. However, in pathological conditions, such as T2D [7] and acute myocardial infarction (AMI) [8], NO bioavailability in the vasculature decreases and eNOS becomes uncoupled producing 
superoxide anion instead of NO [6]. A major cause for eNOS uncoupling is likely to be a deficiency of the NOS cofactor tetrahydrobiopterin $\left(\mathrm{BH}_{4}\right)$ [9]. Under pathological conditions, associated with increased oxidative stress, superoxide anion and peroxynitrite can oxidize $\mathrm{BH}_{4}$, leading to $\mathrm{BH}_{4}$ deficiency [10].

Peroxisome proliferator-activated receptors (PPARs) belong to a subfamily of the nuclear receptors involved in glucose and lipid metabolism; the group includes three isotypes encoded by different genes: $\operatorname{PPAR} \alpha, \operatorname{PPAR} \beta / \delta$, and PPAR $\gamma$ [11]. PPAR $\alpha$ was the first to be discovered and it causes cellular peroxisome proliferation in rodent liver [12], giving this receptor family its name. PPAR $\alpha$ is highly expressed in the heart, liver, kidney, intestine, and brown adipose tissue, all of which are characterized by an elevated rate of fatty acid catabolism [11]. Recently, in our laboratory we observed that the stimulation of PPAR $\alpha$ with clofibrate restores eNOS function and decreases oxidative stress in a rat model of hypertension secondary to aortic coarctation (AoCo) [13]. Moreover, it has been observed that PPAR $\alpha$ ligands, including fibrates, reduce myocardial ischemia/reperfusion (I/R) injury in diabetic and nondiabetic animals; this cardioprotection might be mediated through anti-inflammatory mechanisms and via the activation of the phosphatidylinositol-4,5-bisphosphate 3-kinase (PI3K)/protein kinase B (Akt)/NO pathway $[8,14,15]$. Recently, Barreto-Torres et al. [16] showed that metformin, a widely used antidiabetic drug for T2D, exerts cardioprotection in rats with myocardial $\mathrm{I} / \mathrm{R}$ injury via activation of PPAR $\alpha$.

Therefore, the aim of this work was to test whether the PPAR $\alpha$ activators fenofibrate and metformin and/or their combination exerts an antioxidant effect and preserves $\mathrm{NO}$ production leading to cardioprotection. We also aimed to evaluate the effectiveness of the treatments producing cardioprotection in a rat model of T2D and AMI.

\section{Material and Methods}

All animal procedures were conducted in accordance with Federal Regulations concerning Animal Experimentation and Care (Ministry of Agriculture, SAGARPA, NOM-062ZOO-1999, Mexico). Animal protocol experimentation was approved by the Ethical Committee of our institution (CICUAL, Protocol 502-12) and conducted according to the Guidelines for Care and Use of Experimental Animals.

2.1. Animals. Neonate male Wistar rats (3-4 days old) were divided into 2 groups. Control- (CT-) rats received $0.1 \mathrm{M}$ citrate buffer, $\mathrm{pH} 4.5$ (vehicle), intraperitoneally (i.p.); and diabetic- (DB-) rats received a single streptozotocin (STZ) dose in vehicle $(70 \mathrm{mg} / \mathrm{kg}$, i.p.). Body weight and blood glucose levels were measured weekly during 8 weeks. Blood from the tail was collected for capillary glucose determination in fasted and nonfasted rats using a glucometer (AccuChek Active, Glucotrend, Roche ${ }^{\circledR}$ ). Eight weeks after STZ administration, we conducted an oral glucose tolerance test (OGTT) and determined insulin secretion (these tests were performed with 14 hours of fasting). At this stage, animals from both experimental groups were randomly subdivided to receive one of the subchronic (14 days) oral treatments: (a) vehicle $(\mathrm{NaCl} 0.9 \%)$, (b) fenofibrate $(100 \mathrm{mg} / \mathrm{kg}),(\mathrm{c})$ metformin $(100 \mathrm{mg} / \mathrm{kg})$, (d) metformin $(300 \mathrm{mg} / \mathrm{kg})$, or (e) fenofibrate $(50 \mathrm{mg} / \mathrm{kg})+$ metformin $(50 \mathrm{mg} / \mathrm{kg})$. At the end of the treatment, rats were assigned to either sham-operation or myocardial ischemia for $30 \mathrm{~min}$ followed by $120 \mathrm{~min}$ of reperfusion.

2.2. Acute Myocardial Infarction in Rats. At the end of the subchronic treatment, the rats were anesthetized with a combination of ketamine hydrochloride $(80 \mathrm{mg} / \mathrm{kg}$, i.m.) and xylazine hydrochloride $(10 \mathrm{mg} / \mathrm{kg}$, i.m.). The animals were intubated and artificially ventilated (50 strokes/min, $8-10 \mathrm{~mL} / \mathrm{kg}$ tidal volume). A left intercostal thoracotomy was performed to expose the heart; subsequently myocardial ischemia was induced by the occlusion of the left anterior descending coronary artery (LAD) with a 6-0 silk suture through myocardial tissue. After $30 \mathrm{~min}$ of ischemia, the occlusion was released and the myocardium was reperfused for $120 \mathrm{~min}$. Control animals (sham-operation) were treated in a similar fashion, except for LAD tie.

2.3. Determination of Infarct Size. After $120 \mathrm{~min}$ of reperfusion, the LAD was reoccluded and $1.5 \mathrm{~mL}$ of $2 \%$ Evans blue dye was injected into the right atrium via the left jugular vein to outline the ischemic myocardium (area at risk). The rats were euthanized and the hearts were rapidly excised. The hearts were frozen at $-20^{\circ} \mathrm{C}$ for 1 hour and then cross sections of $2 \mathrm{~mm}$ thickness were performed. The slices were incubated with 2,3,5-triphenyltetrazolium hydrochloride at $1 \%$ in phosphate buffer $(0.1 \mathrm{M}, \mathrm{pH} 7.4)$ for $15 \mathrm{~min}$ at $37^{\circ} \mathrm{C}$ to distinguish the viable myocardium from the necrotic. After overnight incubation in $10 \%$ formalin, the slices were scanned from both sides and weight was obtained. The extent of myocardial necrosis and the area at risk were determined by planimetry (Image J).

2.4. Ex Vivo Cardiac Function Evaluation. After subchronic treatment and sham or $\mathrm{I} / \mathrm{R}$, the hearts of CT- and DB-rats were excised, rapidly cannulated retrogradely through the ascending aorta onto a Langendorff system, and perfused with Krebs-Henseleit buffer $\left(37^{\circ} \mathrm{C}\right)$ saturated with $95 \% \mathrm{O}_{2} / 5 \%$ $\mathrm{CO}_{2}$ at $12 \mathrm{~mL} / \mathrm{min}$ constant flow rate. The Krebs-Henseleit buffer consisted of the following (in $\mathrm{mM}$ ): $117.8 \mathrm{NaCl}, 1.2$ $\mathrm{NaH}_{2} \mathrm{PO}_{4} \cdot \mathrm{H}_{2} \mathrm{O}, 0.027$ EDTA, $6.0 \mathrm{KCl}, 1.6 \mathrm{CaCl}_{2} \cdot 2 \mathrm{H}_{2} \mathrm{O}, 1.2$ $\mathrm{MgSO}_{4} \cdot 7 \mathrm{H}_{2} \mathrm{O}, 25 \mathrm{NaHCO}_{3}$, and 5.55 dextrose $\mathrm{pH}$ 7.4. A latex balloon, connected to a pressure transducer (Statham 7320, Statham Instruments, Inc., Hato Rey, Puerto Rico), was inserted into the left ventricle through an incision in the left atrium. The balloon was then filled with Krebs-Henseleit buffer at $10 \mathrm{mmHg}$ steady diastolic pressure. The function of this balloon is to measure the left ventricular pressure (LVP). Coronary perfusion pressure (PP) was measured by means of a pressure transducer (Gould P23ID, Gould Instruments, Cleveland, $\mathrm{OH}$ ) at the level of the right and left ostium. The heart rate was maintained constant by stimulation 
with an epicardial ventricular pacemaker (Grass-SIU5, Grass Instruments Co.), to reach 312 beats/min $(5 \mathrm{~Hz})$. The heart was stabilized for $30 \mathrm{~min}$ and the following hemodynamic parameters were monitored using a computer acquisition data system (Grass 79D, Grass Instruments Co., Quincy, MA): coronary vascular resistance (CVR) was obtained calculating the ratio between PP $(\mathrm{mmHg})$ and flow rate $(\mathrm{mL} / \mathrm{min})$ and mechanical work was obtained as the product of $\mathrm{LVP}(\mathrm{mmHg}) \times$ heart rate (beats $/ \mathrm{min})$.

2.5. Western Blot. Thirty micrograms of protein from myocardial ischemic areas from the different experimental groups was separated on sodium dodecyl sulfate/polyacrylamide gel, transferred to polyvinylidene difluoride membranes, and then blocked with $8 \%$ skim milk in phosphate-buffered saline $\mathrm{pH}$ 7.4. The membranes were incubated overnight at $4^{\circ} \mathrm{C}$ with specific antibodies against PPAR $\alpha(1: 1000$, Santa Cruz Biotechnology, Santa Cruz, CA), guanosine triphosphate cyclohydrolase I (GTPCH-I) (1:1000, Santa Cruz Biotechnology, Santa Cruz, CA), eNOS (1:5000, Santa Cruz Biotechnology, Santa Cruz, CA), or $\beta$-actin (1:20000, Millipore, Darmstadt, Ger). The membranes were incubated for $1 \mathrm{~h}$ at room temperature with their corresponding secondary antibody: goat anti-mouse (1:15000, Jackson ImmunoResearch, PA, USA), goat anti-mouse (1:5000, Jackson ImmunoResearch), donkey anti-goat (1:5000, Jackson ImmunoResearch, PA, USA), or goat anti-mouse (1:40000, Jackson ImmunoResearch, PA, USA). Blots were washed and visualized using a chemiluminescence kit (Immobilon Western, Millipore, MA, USA). Bands were detected employing a ChemiDoc XRS+ system (BIO-RAD, USA). The bands were quantified by densitometry employing the Image Lab 5.0 software. The results are expressed as arbitrary units (AU) of the ratio between protein and $\beta$-actin.

2.6. Measurement of Total Antioxidant Capacity. Total antioxidant capacity (TAC) in serum was determined as previously reported by Ibarra-Lara et al. [17]. Briefly, in a 96-well plate $35 \mu \mathrm{L}$ of serum was placed with $145 \mu \mathrm{L}$ of $0.1 \mathrm{M}$ phosphate buffer $\mathrm{pH} 7.5$ and homogenized at $500 \mathrm{rpm}$ for $200 \mathrm{~s}$. Immediately after, $100 \mu \mathrm{L}$ of diluted serum was transferred to the adjacent well, mixed with $50 \mu \mathrm{L} \mathrm{CuCl}$ $0.01 \mathrm{M}$, and homogenized at $500 \mathrm{rpm}$ for $200 \mathrm{~s}$. Finally, $50 \mu \mathrm{L}$ bathocuproine $0.01 \mathrm{M}$ was added and mixed (500 rpm/200 s). Samples were read at $490 \mathrm{~nm}$ excitation and $190 \mathrm{~nm}$ emission. TAC is expressed as $\mu \mathrm{mol} / \mathrm{L}$ of $\mathrm{Cu}^{2+}$ reduced to $\mathrm{Cu}^{+}$.

2.7. Superoxide Dismutase Activity. The superoxide dismutase (SOD) activity was determined by the method described by Flohé and Otting [18]. Myocardial ischemic areas from the different experimental groups were homogenized in a buffer consisting of $20 \mathrm{mM}$ sodium bicarbonate, $0.02 \%$ Triton X$100, \mathrm{pH} 10.2$. Twenty $\mu \mathrm{L}$ of clarified supernatant from homogenized samples was added to $2.85 \mathrm{~mL}$ of reaction mixture containing $10 \mu \mathrm{M}$ cytochrome $\mathrm{C}, 10 \mu \mathrm{M}$ sodium azide, $100 \mu \mathrm{M}$ xanthine, and $1 \mathrm{mM}$ EDTA in $20 \mathrm{mM}$ sodium bicarbonate, $0.02 \%$ Triton X-100, $\mathrm{pH} 10.2$. The assay was initiated by adding xanthine oxidase. The mixture was homogenized and absorbance determined spectrophotometrically at $550 \mathrm{~nm}$ every 30 seconds for 3 minutes. The activity of manganese SOD (MnSOD) was measured in the same manner as total SOD activity, but the reaction was incubated with $50 \mu \mathrm{L}$ of $\mathrm{KCN}(1 \mathrm{mM})$ to inhibit $\mathrm{Cu} / \mathrm{ZnSOD}$. The difference between total SOD and MnSOD represents $\mathrm{Cu} / \mathrm{ZnSOD}$ activity. Results are expressed as SOD units/mg protein. One unit of SOD is defined as the amount of enzyme that inhibits at $50 \%$ the rate of cytochrome $c$ reduction, under specified conditions.

2.8. Determination of $\mathrm{BH}_{4}$ and $\mathrm{BH}_{2}$ Production. The production of $\mathrm{BH}_{4}$ and $\mathrm{BH}_{2}$ was determined as previously reported by Cervantes-Pérez et al. [13]. Briefly, myocardial ischemic areas from different experimental groups were analyzed by capillary zone electrophoresis (CZE, P/ACE MDQ Capillary Electrophoresis System, Beckman Coulter, Inc., Fullerton, CA, USA) to measure $\mathrm{BH}_{4}$ and $\mathrm{BH}_{2}$ simultaneously. Capillary electrophoretic separation was achieved using a Sep-Pak ${ }^{\circledR}$ Aminopropyl (NH2) Classic Cartridge. Sample separation was performed by applying $30 \mathrm{kV}$ for $10 \mathrm{~min}$ and UV determination was at $230 \mathrm{~nm}$. Data are expressed as pmol of $\mathrm{BH}_{4}$ or $\mathrm{BH}_{2}$ per $\mathrm{mg}$ of wet tissue.

2.9. NOS Activity Determination. Quantification of NOS activity was measured according to Ibarra-Lara et al. [17]. The basis of the technique involved the conversion of $\mathrm{L}-\left[{ }^{3} \mathrm{H}\right]$ arginine into $\mathrm{NO}$ and $\mathrm{L}-\left[{ }^{3} \mathrm{H}\right]$-citrulline, in the presence of the appropriate enzyme cofactors.

2.10. Quantification of NO in Biological Samples. The NO production in myocardial ischemic areas from different experimental groups was evaluated using the technique described by Griess and modified by Tenorio and del Valle [19].

2.11. Statistical Analysis. Results are expressed as mean \pm standard error of the mean (SEM). Experimental data were examined employing the two-way ANOVA followed by Duncan's post hoc test. Statistical significance was set at $P<0.05$. All analyses were carried out using the statistical package Sigma Plot version 12.0 (San Jose, CA, USA).

\section{Results}

3.1. T2D Model. Capillary glucose was determined in fasted and nonfasted rats. In fasting conditions no changes in capillary glucose were observed in CT- or DB-rats (Figure 1(a)), whereas, in nonfasting conditions, DB-rats displayed hyperglycemia compared with the CT group. Regarding body weight, DB-rats showed lower body weight compared to CT-rats (Figure 1(b)). At 8 weeks, DB-rats showed impaired glucose tolerance after glucose load (Figure 1(c)) and insulin secretion was lower compared with the CT group (Figure 1(d)).

Subchronic treatments (14 days) promoted a decrease in body weight in CT-rats (Figure 2(a)). In DB-rats none of the pharmacological treatments modified body weight 

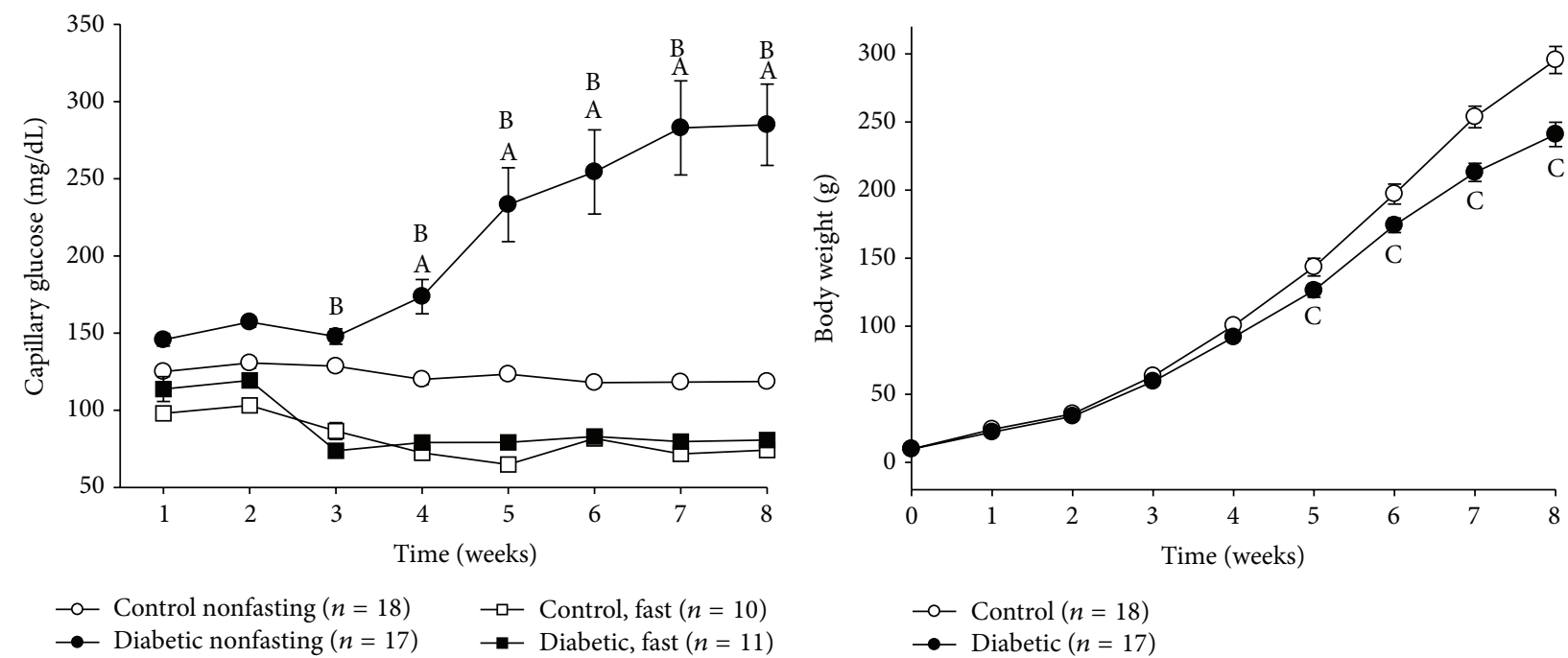

(b)
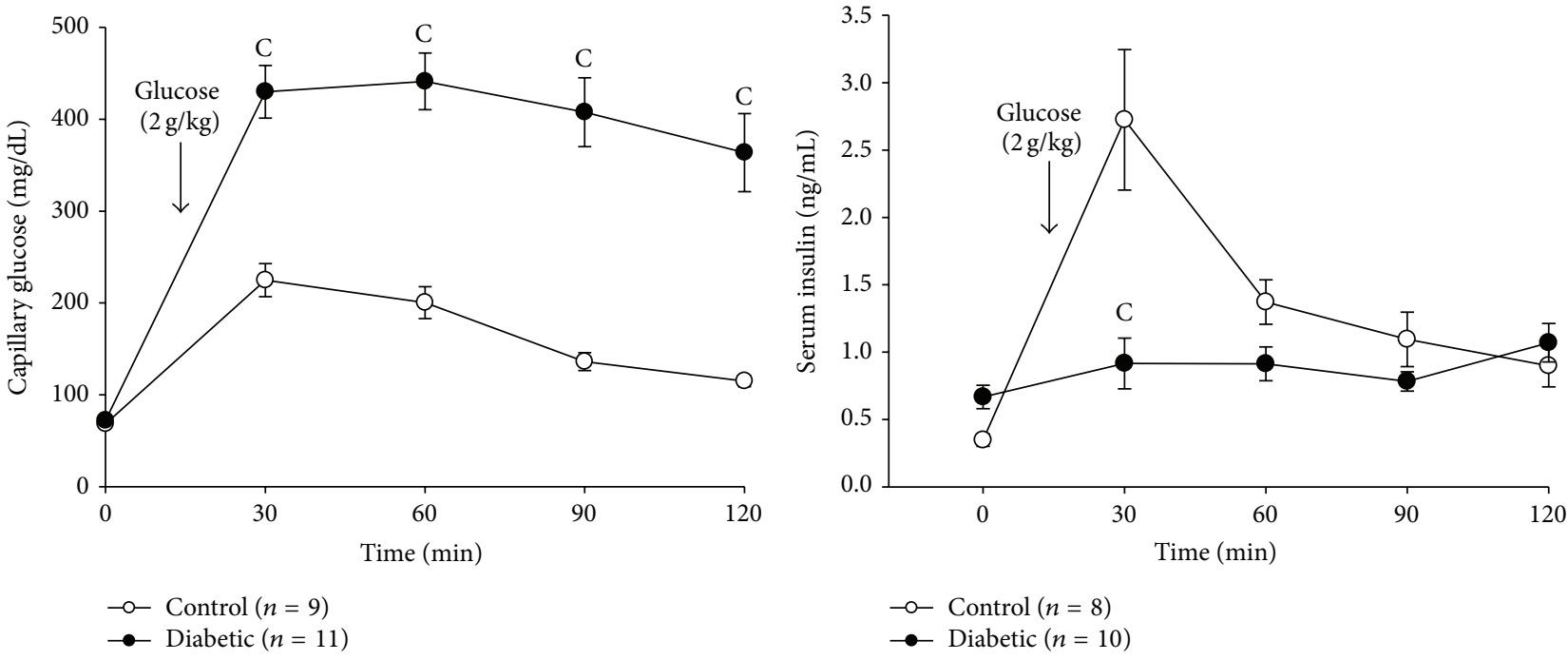

(c)

(d)

FIGURE 1: Characteristics of neonatal streptozotocin-induced T2D rat model. Time-course of (a) capillary glucose concentrations and (b) body weight from control- (CT-) and diabetic- (DB-) rats. (c) Capillary glucose levels and (d) serum insulin concentrations before and during an oral glucose tolerance test (OGTT) $(2 \mathrm{~g} / \mathrm{Kg})$ in 8 -week-old CT- and DB-rats. ${ }^{\mathrm{A}} P<0.05$ versus CT nonfasting, ${ }^{\mathrm{B}} \mathrm{P}<0.05$ versus DB fast, and ${ }^{\mathrm{C}} P<0.05$ versus control two-way ANOVA followed by Duncan's post hoc test.

(Figure 2(a)). Metformin (300 mg/kg) and the combination of fenofibrate $(50 \mathrm{mg} / \mathrm{kg})$ plus metformin $(50 \mathrm{mg} / \mathrm{kg})$ promoted the use of glucose in DB-rats, observed as a decrease in the hyperglycemia (Figure 2(b)). However, none of the pharmacological treatments (fenofibrate, metformin, or their combination) decreased glucose intolerance (Figure 2(c)).

3.2. Hemodynamics. We observed that $\mathrm{I} / \mathrm{R}$ increased $\mathrm{CVR}$ (Figure 3(a)) and decreased cardiac work (Figure 3(b)) in both CT- and DB-rats; CVR was higher in DBI/R rats than in CTI/R rats. Fenofibrate and metformin (100 and $300 \mathrm{mg} / \mathrm{kg}$ ) decreased CVR and increased cardiac work in both $\mathrm{CTI} / \mathrm{R}$ and $\mathrm{DBI} / \mathrm{R}$ rats. Interestingly, the combination exerted synergism observed as decreased CVR and increased cardiac work when compared to controls.
3.3. Infarct Size. No changes in the area at risk were observed among the different groups (Figures 4(a) and 4(b)), suggesting that the LAD's ligation was consistently performed at the same place. Even so, infarct size was greater in DBI/R than in CTI/R rats treated with vehicle. All treatments promoted cardioprotection in CTI/R rats observed as decreased infarct size compared with vehicle-treated CTI/R group. Cardioprotection was also exerted, by the treatments, in $\mathrm{DBI} / \mathrm{R}$ compared with the DBI/R-Vehicle group. Interestingly, the combination of treatments produced cardioprotection comparable to higher doses of individual treatments (Figure 4(c)).

3.4. PPAR $\alpha$ Expression. Our results show that $\mathrm{I} / \mathrm{R}$ decreased PPAR $\alpha$ expression in CT- and DB-rats. In DBI/R, fenofibrate and metformin (100 and $300 \mathrm{mg} / \mathrm{kg}$ ) restored PPAR $\alpha$ 


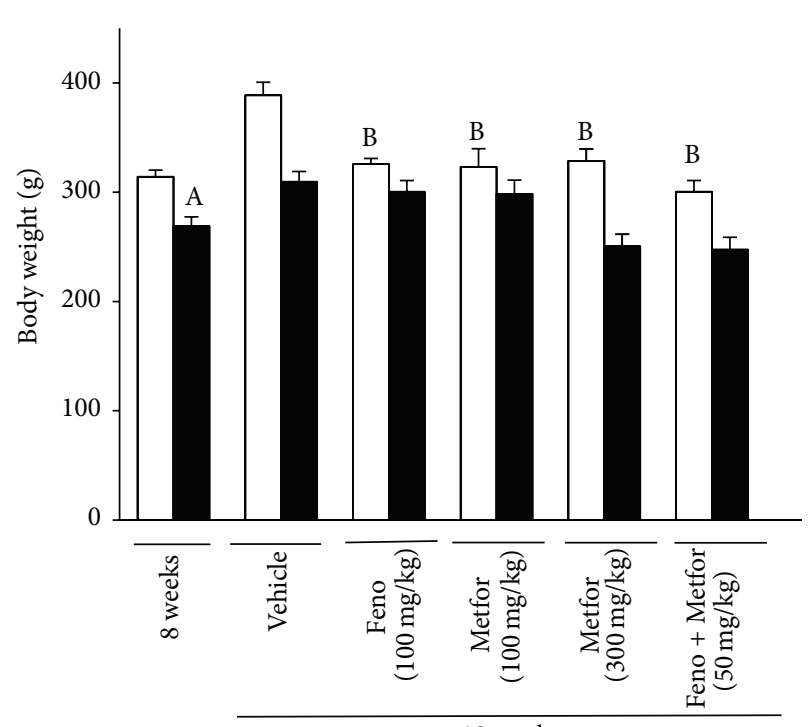

10 weeks

$$
\text { Control }
$$

Diabetic

(a)

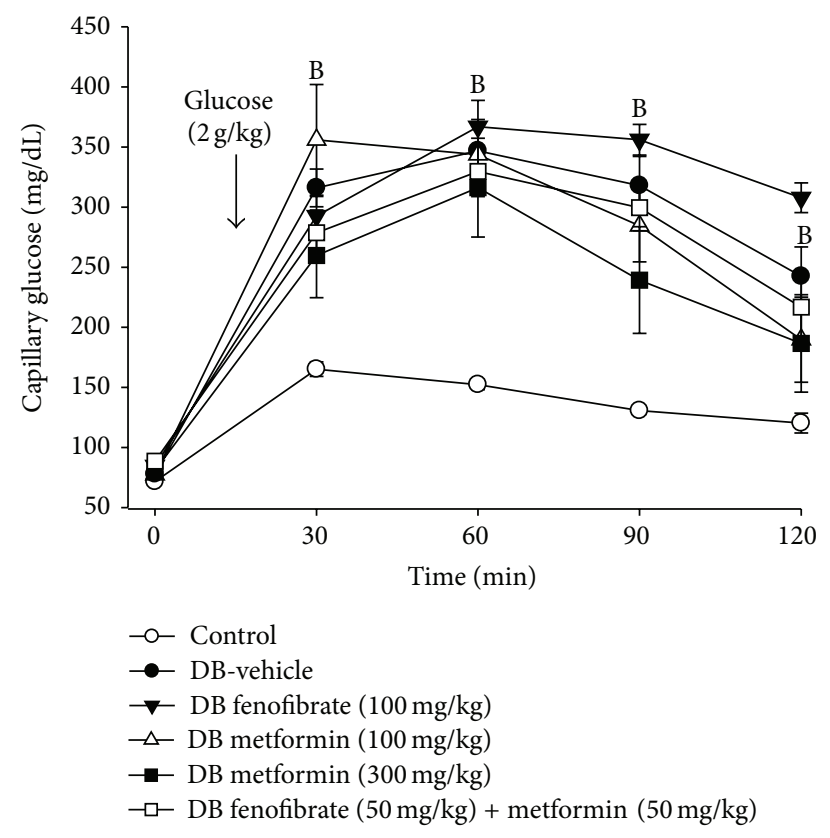

(c)

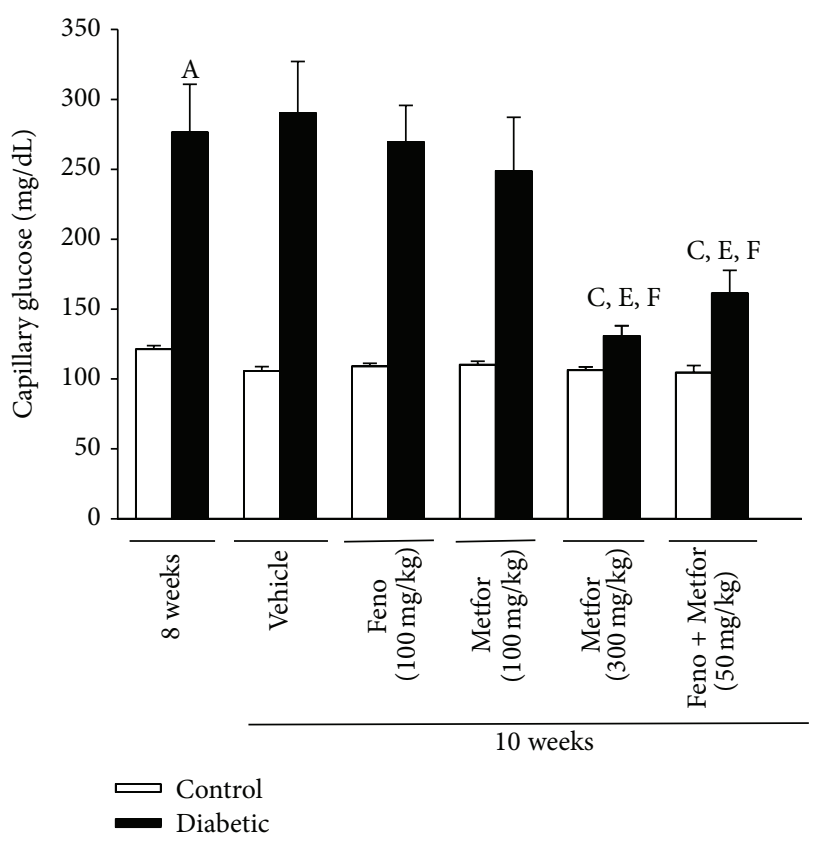

(b)

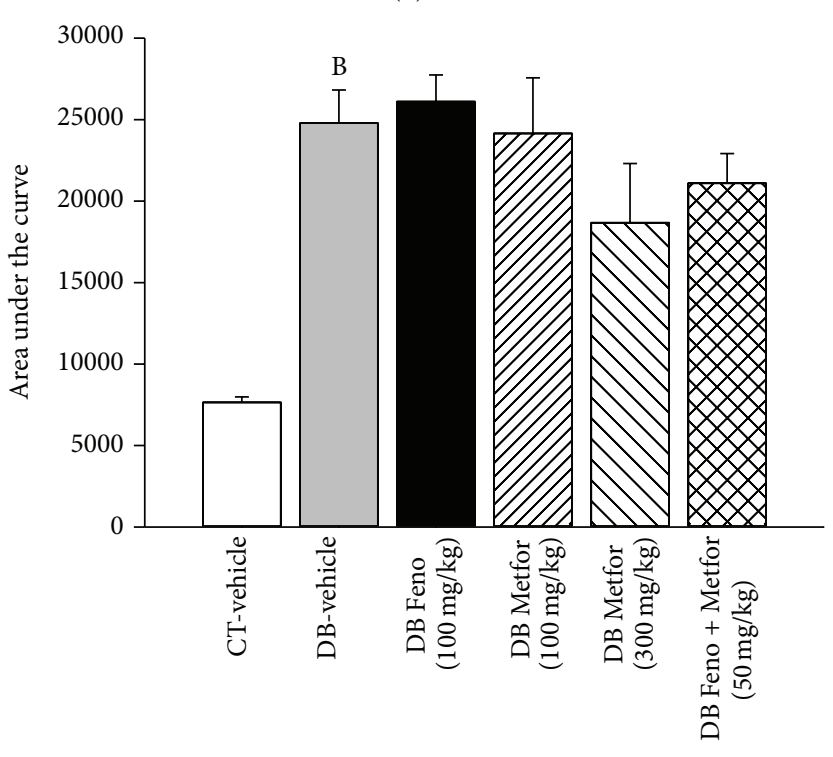

(d)

FIGURE 2: Effect of subchronic treatment (14 days) of different drugs on (a) body weight and (b) nonfasting capillary glucose concentrations of control- (CT-) and diabetic- (DB-) rats. (c) Capillary glucose levels in CT- and DB-rats before and during an oral glucose tolerance test (OGTT) $\left(2 \mathrm{~g} / \mathrm{kg}\right.$ ) after 14 days of subchronic treatment. (d) Area under the curve for OGTT. ${ }^{\mathrm{A}} P<0.05$ versus CT, ${ }^{\mathrm{B}} P<0.05$ versus CT-vehicle, ${ }^{\mathrm{C}} P<0.05$ versus DB-vehicle, ${ }^{\mathrm{E}} P<0.05$ versus fenofibrate (Feno, $100 \mathrm{mg} / \mathrm{kg}$ ), and ${ }^{\mathrm{F}} P<0.05$ versus metformin (Metfor, $100 \mathrm{mg} / \mathrm{kg}$ ) two-way ANOVA followed by Duncan's post hoc test. Data are presented as means \pm SEM of 6 animals per group.

expression to control values. In CTI/R treatments did not modify the PPAR $\alpha$ expression. Even though no statistical difference was found in DBSH-rats, a clear tendency of increased PPAR $\alpha$ expression is observed in fenofibrate- and metformin- (100 and $300 \mathrm{mg} / \mathrm{kg}$ ) treated rats (Figures $5(\mathrm{a})$ and 5(b)).
3.5. Total Antioxidant Capacity. As shown in Figure 6, I/R and $\mathrm{DB}$ lowered the TAC; this event was prevented by fenofibrate and metformin in CTI/R. In terms of nonischemic DB-rats, treatments did not affect the TAC. The combination of treatments increased the TAC in I/R, DBSH, and DBI/R groups compared to control values. 


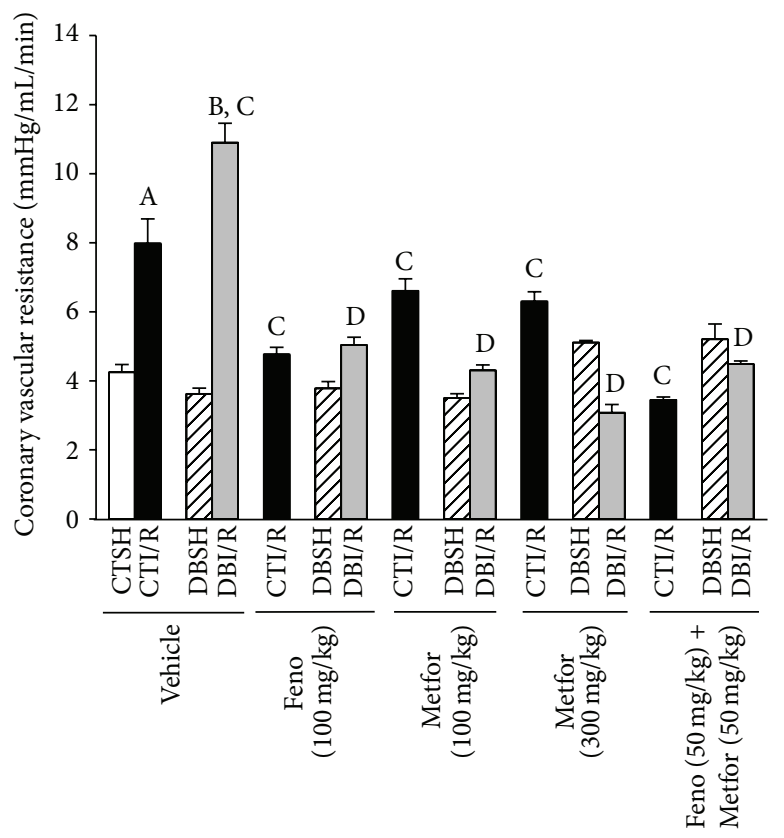

(a)

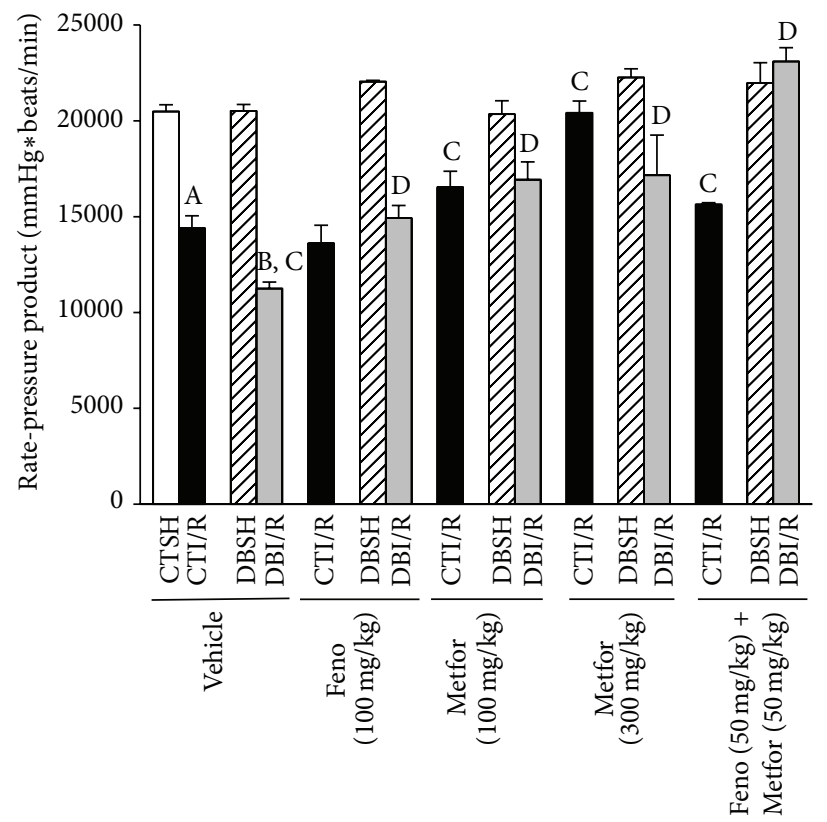

(b)

Figure 3: Evaluation of the ex vivo cardiac hemodynamics in control-ischemia/reperfusion (CTI/R) and diabetic-ischemia/reperfusion (DBI/R) conditions. (a) Coronary vascular resistance and (b) rate-pressure product were both measured ex vivo by Langendorff technique. ${ }^{\mathrm{A}} P<0.05$ versus control-sham- (CTSH-) Vehicle, ${ }^{\mathrm{B}} P<0.05$ versus diabetic-sham- (DBSH-) Vehicle, ${ }^{\mathrm{C}} P<0.05$ versus CTI/R-Vehicle, and ${ }^{\mathrm{D}} P<0.05$ versus DBI/R-Vehicle two-way ANOVA followed by Duncan's post hoc test. Data are presented as means \pm SEM of 6 animals per group.

3.6. SOD Activity. With respect to $\mathrm{Cu} / \mathrm{ZnSOD}$ activity, metformin (100 and $300 \mathrm{mg} / \mathrm{kg}$ ) promoted an increase only in $\mathrm{DBI} / \mathrm{R}$ rats compared to the $\mathrm{DBI} / \mathrm{R}-$ Vehicle group (Figure 7(a)). In DB-rats, MnSOD activity decreased in both sham- and I/R-subjected rats treated with vehicle compared to CTSH-Vehicle. Fenofibrate $(100 \mathrm{mg} / \mathrm{kg})$ increased the MnSOD activity in DBSH- and DBI/R rats compared to those treated with vehicle. While metformin $(100 \mathrm{mg} / \mathrm{kg})$ enhanced MnSOD activity only in $\mathrm{DBI} / \mathrm{R}$ conditions, metformin (300 mg/kg) improved it also in CTI/R and DBI/R conditions. Interestingly, the combination of treatments increased the MnSOD activity in every experimental group (Figure 7(b)).

3.7. GTPCH-I Expression and $\mathrm{BH}_{2}, \mathrm{BH}_{4}$ Production. The expression of GTPCH-I decreased in CTI/R compared with CTSH-Vehicle. In DBSH-rats, none of the treatments significantly altered the expression of GTPCH-I. Fenofibrate and metformin (100 and $300 \mathrm{mg} / \mathrm{kg}$ ) increased GTPCH-I expression in $\mathrm{CTI} / \mathrm{R}$ and $\mathrm{DBI} / \mathrm{R}$ groups. Interestingly, the combination of treatments (at lower doses than individually administered) increased GTPCH-I expression in both CTI/R and DBI/R groups (Figure $8(\mathrm{a})$ ). Due to the high relevance of $\mathrm{BH}_{4}$ as a cofactor for eNOS to produce NO, we measured $\mathrm{BH}_{4}: \mathrm{BH}_{2}$ ratio. As shown in Figure $8(\mathrm{~b}), \mathrm{I} / \mathrm{R}$ and $\mathrm{DB}$ decreased $\mathrm{BH}_{4}: \mathrm{BH}_{2}$ ratio. In DBSH-rats, none of the treatments significantly modified the $\mathrm{BH}_{4}: \mathrm{BH}_{2}$ ratio. However, fenofibrate and metformin (100 and $300 \mathrm{mg} / \mathrm{kg}$ ), as well as the combination of fenofibrate and metformin, increased $\mathrm{BH}_{4}: \mathrm{BH}_{2}$ ratio in CTI/R and DBI/R groups (Figure $8(\mathrm{~b})$ ).
3.8. eNOS Expression and NOS Activity. Our data show that eNOS expression remained comparable among groups, regardless of the treatments (Figure 9(a)). Endothelial NOS activity diminished in the left ventricular ischemic zone in response to both I/R and DB. Fenofibrate and metformin (100 and $300 \mathrm{mg} / \mathrm{kg}$ ) increased eNOS activity in both CTI/R and $\mathrm{DBI} / \mathrm{R}$ rats. In $\mathrm{DBSH}$, none of the treatments significantly modified eNOS activity. The administration of fenofibrate + metformin improved the activity of eNOS bringing values closer to those of controls (Figure 9(c)). Since iNOS plays an important role in numerous pathophysiological conditions, for example, I/R and DB, we measured its activity. Our results show that I/R and DB increased iNOS activity, fenofibrate was able to prevent the rise in iNOS activity in $\mathrm{DB}$, and metformin and the combination of treatments prevented the activation of iNOS in I/R and DB groups (Figure 9(d)).

3.9. NO Production. The data show that NO production decreased in the left ventricles from rats under I/R and DB conditions. Fenofibrate, metformin (100 and $300 \mathrm{mg} / \mathrm{kg}$ ), and their combination prevented the NO reduction in CTI/R and $\mathrm{DBI} / \mathrm{R}$ groups. However, none of the treatments significantly modified the NO production in DBSH-rats (Figure 9(b)).

\section{Discussion}

We demonstrated that fenofibrate, metformin, and the combination of treatments, at low doses, generate cardioprotection in an experimental model of T2D subjected to 

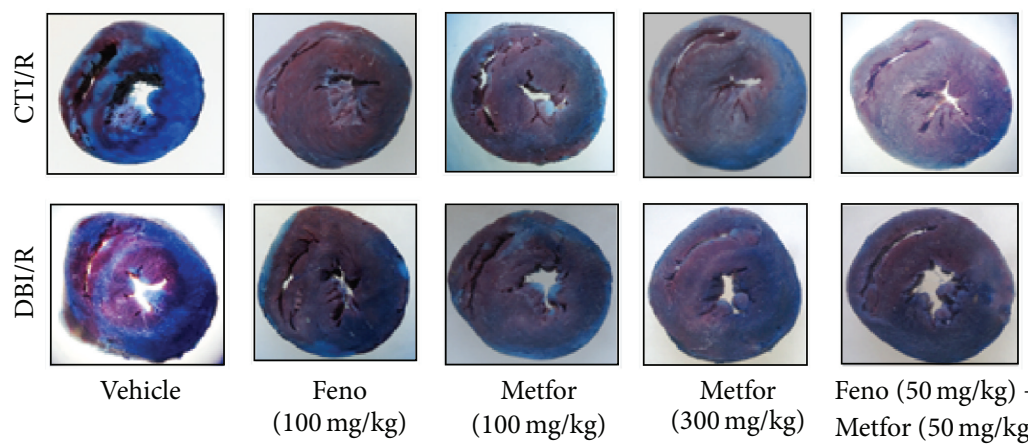

(a)

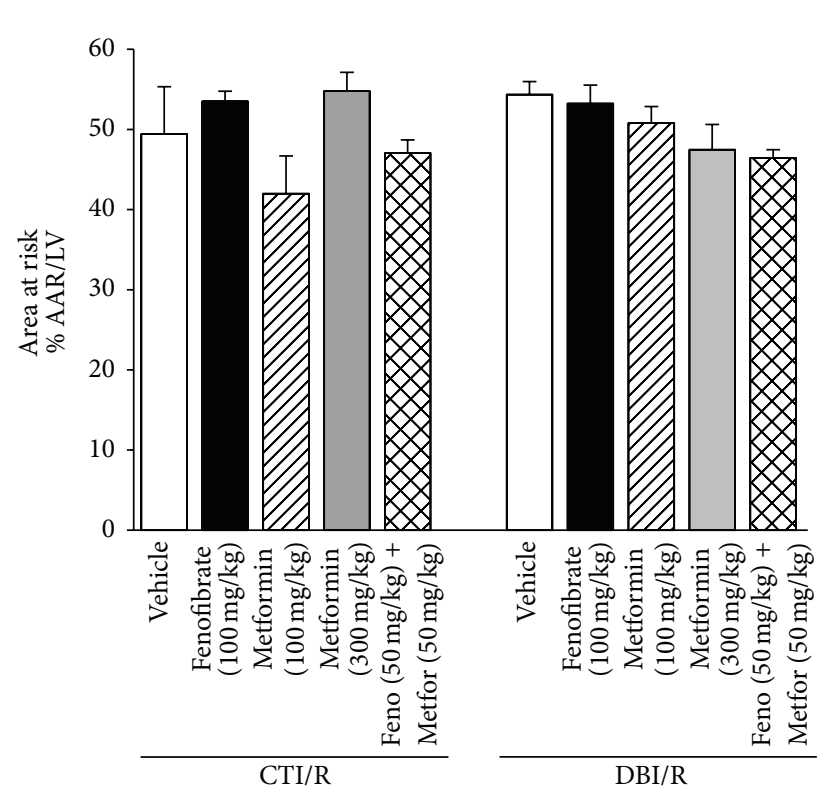

(b)

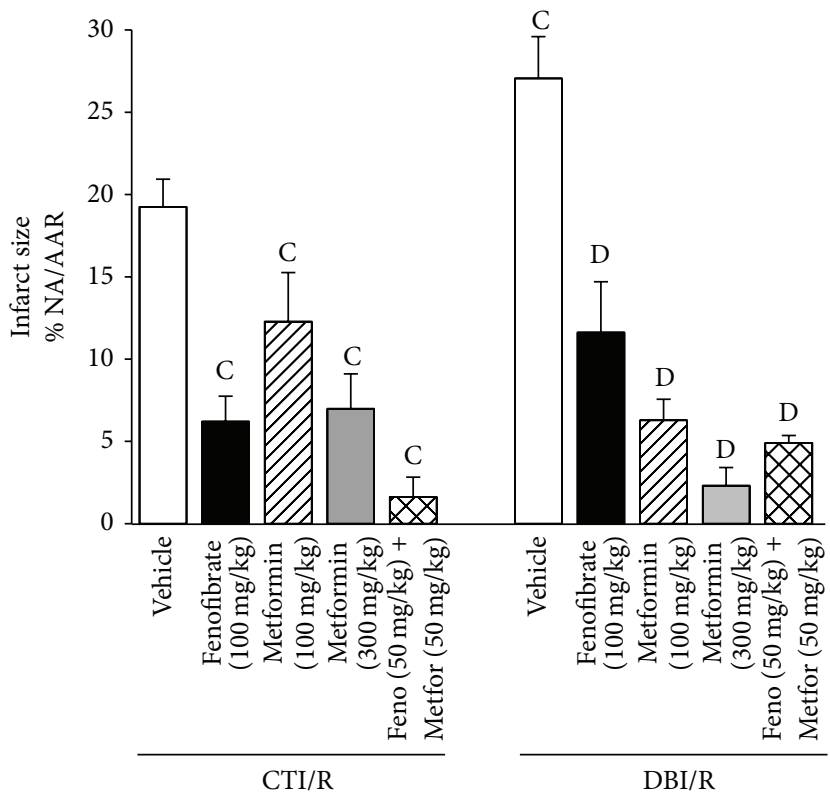

(c)

FIGURE 4: Subchronic treatment with fenofibrate (F), metformin (M), and their combination reduced infarct size in control-ischemia/reperfusion (CTI/R) and diabetic-ischemia/reperfusion (DBI/R) conditions. (a) Representative photographs of Evans blue/triphenyltetrazolium chloride dyed heart slices from CTI/R and DBI/R rats, the blue area represents the area with viable tissue, the red area is the area at risk (AAR), and the white regions are the necrotic areas (NA). (b) Area at risk and (c) infarct size of the different groups, expressed as a percentage of AAR in the left ventricle and percentage of NA in the AAR, respectively. ${ }^{\mathrm{C}} P<0.05$ versus CTI/R-Vehicle and ${ }^{\mathrm{D}} P<0.05$ versus DBI/R-Vehicle two-way ANOVA followed by Duncan's post hoc test. Data are presented as means \pm SEM of 4-6 animals per group.

I/R. Pharmacological treatments prevented the rise in CVR, decreased cardiac output, and decreased infarct size; those effects were most probably achieved through the activation of $\operatorname{PPAR} \alpha$ which promoted an antioxidant effect preserving NO bioavailability therefore improving endothelial functioning.

It has been shown that PPAR $\alpha$ expression is downregulated by chronic diabetes stressors [20] and hypoxia inducible factor-1 (HIF-1) [21]. According to that reported, we observed that, in DBSH and DBI/R subjects, the expression of $\operatorname{PPAR} \alpha$ decreases compared with the CTSH-Vehicle group. Interestingly, in fenofibrate- and metformin-treated DBSHrats there is a clear tendency to raise $\operatorname{PPAR} \alpha$ expression compared with DBSH-Vehicle. The combination of treatments did not modify PPAR $\alpha$ expression in DBI/R group compared to vehicle-treated rats. This lack of stimulation for protein expression could be due to the low dose; however it was sufficient to promote cardioprotective effects.

T2D is associated with increased cardiovascular disease rates, raising the risk of myocardial infarction [2]. Patients with T2D exhibit several abnormalities in left ventricular function and impaired cardiac contractility, including reduced stroke volume, elevated end-diastolic pressure, shortened ejection time, and prolonged preejection period [22]. Interestingly, in the neonatal streptozotocin-treated rat (n-STZ) model, the extent to which cardiac performance is affected appears to be dependent on the duration of STZ treatment. Schaffer et al. [23] demonstrated that at 4 months there appears to be no mechanical dysfunction; however, at 8 and 12 months diabetic hearts showed significantly depressed cardiac function, observed as decreased aortic 


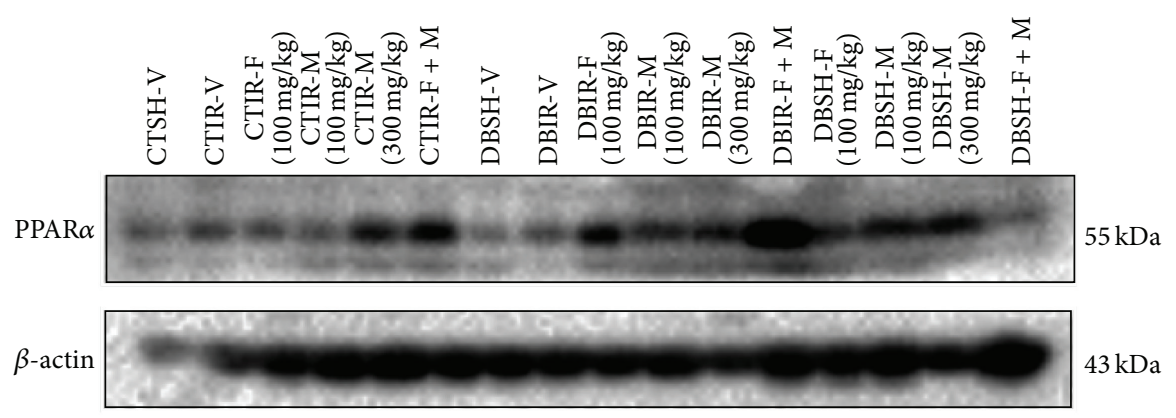

(a)

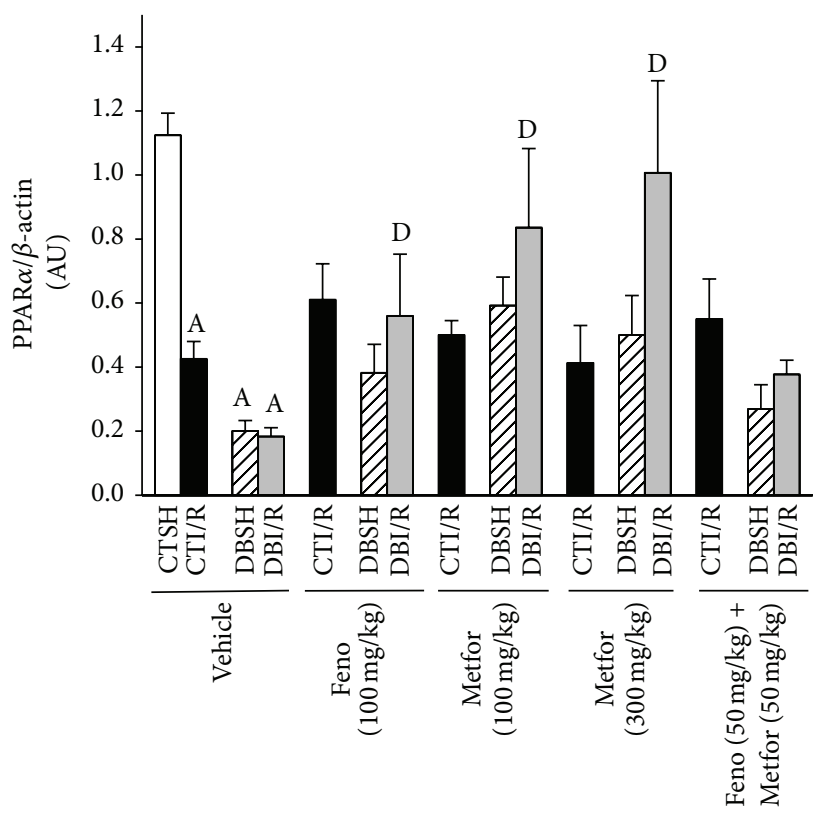

(b)

FIGURE 5: Subchronic treatment with fenofibrate (F), metformin (M), and their combination prevented the decreased expression of PPAR $\alpha$ in diabetic-ischemia/reperfusion (DBI/R) conditions. (a) Representative immunoblot and (b) PPAR $\alpha$ expression in ischemic left ventricle area $\left(n=4\right.$ rats/group). ${ }^{\mathrm{A}} P<0.05$ versus control-sham- (CTSH-) Vehicle and ${ }^{\mathrm{D}} P<0.05$ versus DBI/R-Vehicle two-way ANOVA followed by Duncan's post hoc test. Data are presented as means \pm SEM.

output, decreased ventricular pressure, and decreased cardiac work. With respect to cardiovascular hemodynamics, we did not observe changes in the CVR and cardiac work in 10-weekold DBSH-rats, probably due to animals' age and chronicity of the pathology of the DB-rats. However, after an ischemic insult, DBI/R rats exhibit increased CVR, decreased cardiac work, and increased infarct size compared to nondiabetic rats resembling T2D patients who experience a more adverse outcome after acute myocardial infarction compared with nondiabetic patients [24]. Our study demonstrates that the $\operatorname{PPAR} \alpha$ activators fenofibrate and metformin and the combination of treatments generate cardioprotection preventing the increase of CVR and the decreased cardiac output as well as decreasing infarct size. Our research is the first study to demonstrate that the combination of fenofibrate and metformin, at low doses, generates cardioprotection probably by the activation of PPAR $\alpha$.

Pharmacological stimulation of PPAR $\alpha$ elicits a wide array of effects. It has been reported that $\operatorname{PPAR} \alpha$ agonists increase sensitivity to insulin-stimulated glucose uptake to a substantial degree in animal insulin resistance models and in ex vivo human muscle cells studies [25]. However, Rieusset et al. [26] reported that in human subjects with T2D there was no difference in insulin sensitivity after subchronic treatment with fenofibrate compared with control. Our results agree with Rieusset, since no evidence of decreased hyperglycemia or improvement in glucose tolerance in DB-rats, after a subchronic treatment with a selective PPAR $\alpha$ agonist (fenofibrate) compared with CT-rats, was observed, suggesting that the cardioprotector effect is not due to glucose lowering effect. Moreover, metformin, the first-line pharmacological treatment in the management of T2D, reported to improve glycemic control [27], at a dose of $100 \mathrm{mg} / \mathrm{kg}$, did not improve the glucose tolerance in DB- compared with CT-rats. In our study, the subchronic treatment with fenofibrate and metformin, at low doses, lowers the hyperglycemia but does not improve the glucose tolerance in DB-rats compared with CT-rats, an effect most probably mediated by PPAR $\alpha$. 


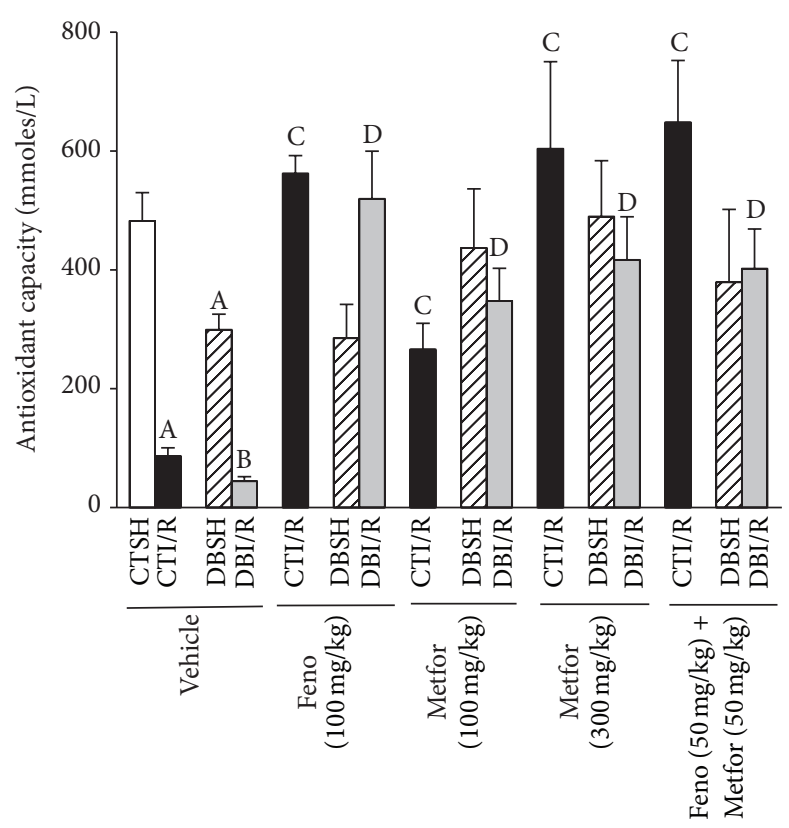

FIGURE 6: Effect of fenofibrate, metformin, and fenofibrate + metformin on serum antioxidant capacity. Total antioxidant capacity was evaluated in serum from control- (CT-) and diabetic- (DB-) rats subjected to sham- (SH-) or ischemia/reperfusion- (I/R-) myocardial infarction and treated subchronically (14 d) with either vehicle, fenofibrate (Feno, $100 \mathrm{mg} / \mathrm{kg}$ ), metformin (Metfor, $100 \mathrm{or} 300 \mathrm{mg} / \mathrm{kg}$ ), or Feno $(50 \mathrm{mg} / \mathrm{kg})+$ Metfor $(50 \mathrm{mg} / \mathrm{kg})$. Data are presented as means \pm SEM $(n=6-14$ rats $/$ group $) .{ }^{\mathrm{A}} P<0.05$ versus CTSH-Vehicle, ${ }^{\mathrm{B}} P<0.05$ versus DBSH-Vehicle, ${ }^{\mathrm{C}} \mathrm{P}<0.05$ versus CTI/R-Vehicle, and ${ }^{\mathrm{D}} \mathrm{P}<0.05$ versus DBI/R-Vehicle two-way ANOVA followed by Duncan's post hoc test.

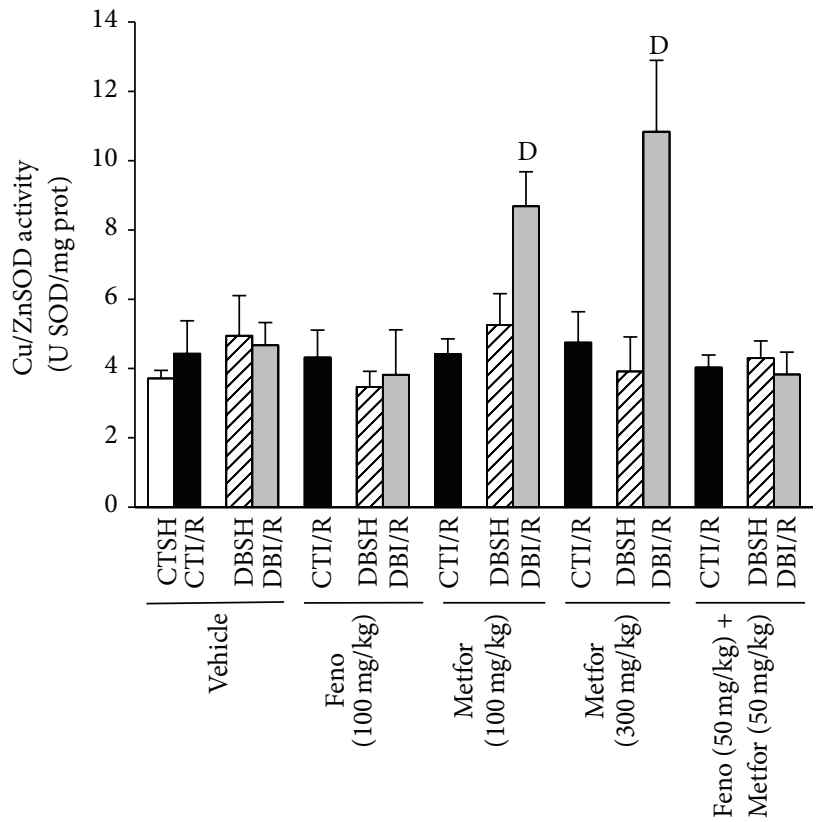

(a)

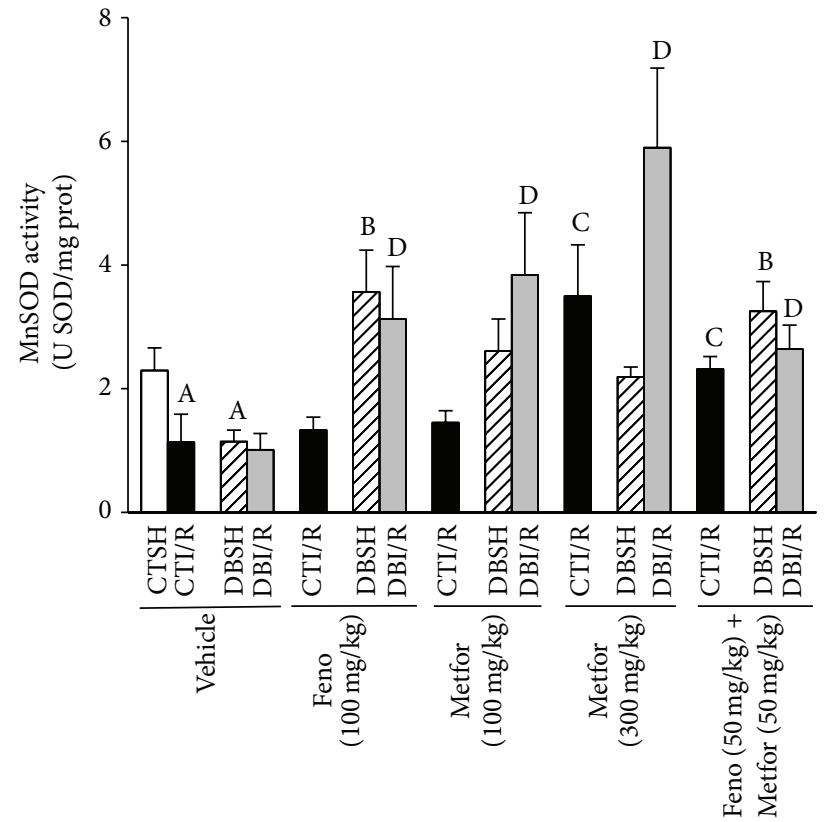

(b)

Figure 7: Effect of the treatments on $\mathrm{Cu} / \mathrm{ZnSOD}$ and MnSOD activity, evaluated in ischemic left ventricle area from control- (CT-) and diabetic- (DB-) rats subjected to sham- (SH-) or ischemia/reperfusion- (I/R-) myocardial infarction and treated subchronically (14 d) with either vehicle, fenofibrate (Feno, $100 \mathrm{mg} / \mathrm{kg}$ ), metformin (Metfor, 100 or $300 \mathrm{mg} / \mathrm{kg}$ ), or Feno $(50 \mathrm{mg} / \mathrm{kg}$ ) + Metfor (50 mg/kg). (a) Cu/ZnSOD and (b) MnSOD activity ( $n=4-6$ rats/group). ${ }^{\mathrm{A}} P<0.05$ versus CTSH-Vehicle, ${ }^{\mathrm{B}} P<0.05$ versus DBSH-Vehicle, ${ }^{\mathrm{C}} P<0.05$ versus CTI/RVehicle, and ${ }^{\mathrm{D}} P<0.05$ versus DBI/R-Vehicle two-way ANOVA followed by Duncan's post hoc test. Data are presented as means \pm SEM. 


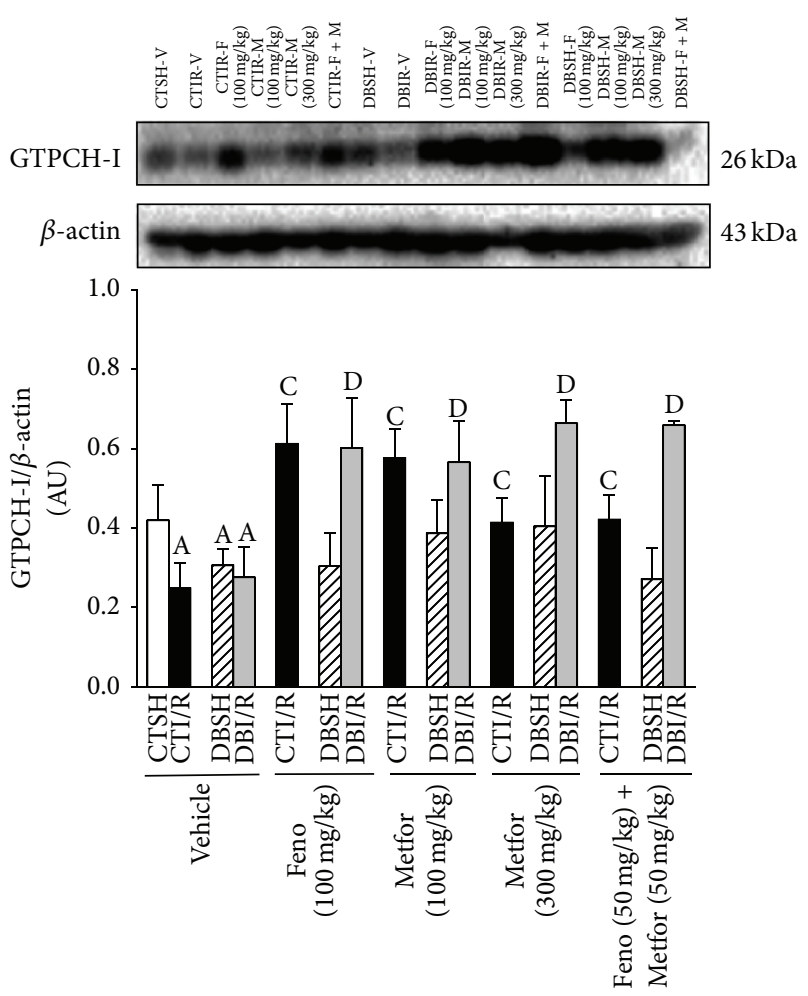

(a)

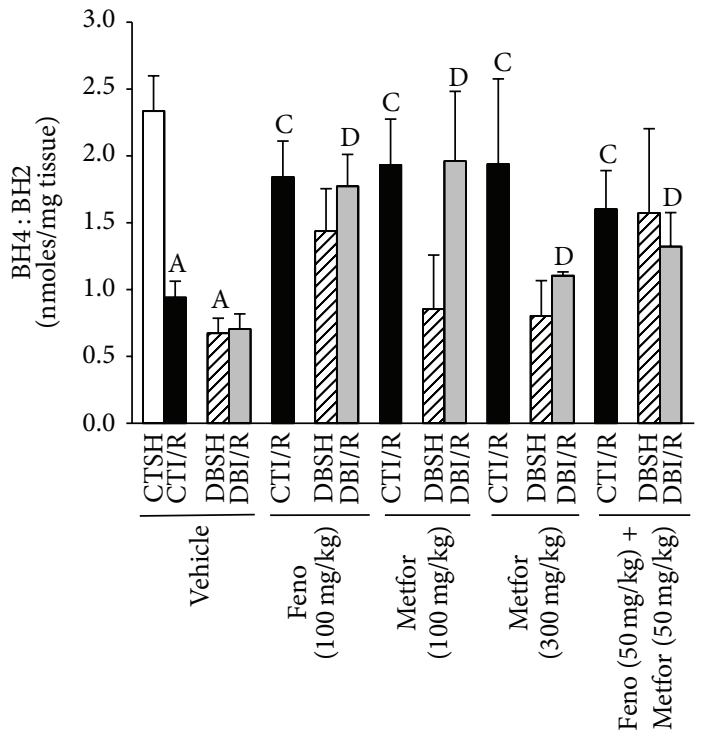

(b)

FIGURE 8: Subchronic treatment with fenofibrate (F), metformin (M), and their combination increases GTPCH-I expression and $\mathrm{BH}_{4}: \mathrm{BH}_{2}$ ratio in both control- (CT-) and diabetic- (DB-) rats subjected to ischemia/reperfusion (I/R). GTPCH-I expression was evaluated in ischemic left ventricle area from CT- and DB-rats subjected to sham- (SH-) or I/R-myocardial infarction and treated subchronically (14 d) with either vehicle, fenofibrate (F, $100 \mathrm{mg} / \mathrm{kg}$ ), metformin (M, 100 or $300 \mathrm{mg} / \mathrm{kg}$ ), or Feno (50 mg/kg) + Metfor (50 mg/kg). (a) Representative immunoblot and GTPCH-I expression ( $n=4$ rats/group) and (b) $\mathrm{BH}_{4}: \mathrm{BH}_{2}$ ratio $\left(n=4-6\right.$ rats/group). ${ }^{\mathrm{A}} P<0.05$ versus CTSH-Vehicle, ${ }^{\mathrm{C}} P<0.05$ versus CTI/R-Vehicle, and ${ }^{\mathrm{D}} P<0.05$ versus DBI/R-Vehicle two-way ANOVA followed by Duncan's post hoc test. Data are presented as means \pm SEM.

Although the effects of fenofibrate are classically mediated via activation of $\operatorname{PPAR} \alpha$, several studies have demonstrated PPAR $\alpha$-independent effects. Likewise, fenofibrate is able to exert anti-inflammatory [28, 29], antifibrotic [30], antihyperthrophic [31], and proapoptotic [32] effects in a PPAR $\alpha$-independent way. Similarly, metformin is capable of interaction with several molecular targets including the activation of the reperfusion injury salvage kinase (RISK) pathway [33], by increasing AMPK activation [34] or via adenosine receptor stimulation [35], both of them actions that inhibit the mitochondrial permeability transition pore (mPTP) opening at reperfusion exerting cardioprotection.

We propose that fenofibrate and metformin activate $\operatorname{PPAR} \alpha$ generating cardioprotection against I/R injury in $n-$ STZ model, through a mechanism that involves decreased oxidative stress and increased NO bioavailability. We based our hypothesis on current and previous data reporting that clofibrate lowers oxidative stress, enhances NO bioavailability, and improves ultrastructure and ventricular hemodynamics in no-flow myocardial ischemia in rats [17]. Further, numerous studies have demonstrated cardioprotective effects of NO during I/R in T2D and nondiabetic models $[8,36$, 37]. It is widely reported that $\mathrm{NO}$ possesses a number of physiological properties, such as vasodilation, inhibition of oxidative stress, platelet aggregation, leukocyte chemotaxis, and apoptosis, which make it a potent cardioprotectivesignaling molecule $[9,10]$. Under pathological conditions, such as T2D [7] and AMI [8], NO bioavailability in the vasculature decreases and eNOS becomes uncoupled producing superoxide anion instead of $\mathrm{NO}$, increasing oxidative stress and leading to endothelial dysfunction [6]. In accordance with the literature, we observed that, in AMI (I/R) and T2D, parameters like NO bioavailability, MnSOD activity, and the total antioxidant capacity decreased. We also showed that fenofibrate + metformin prevented those changes in CTI/R and DBI/R. Regarding the increased bioavailability of $\mathrm{NO}$, it is most probably due to increased eNOS activity, since we observed a raise in this parameter, no change in eNOS expression was observed, and previous data have shown that PPAR $\alpha$ stimulation promotes eNOS phosphorylation at Ser1177 [7].

Endothelial NOS strictly requires $\mathrm{BH}_{4}$ in order to be coupled and produce $\mathrm{NO}$ [10]. Deficient $\mathrm{BH}_{4}$ levels in several in vitro and in vivo models have correlated with low $\mathrm{NO}$ production [38]. Therefore, $\mathrm{BH}_{4}$ availability is a critical determinant of eNOS regulation in several pathologies (e.g., 


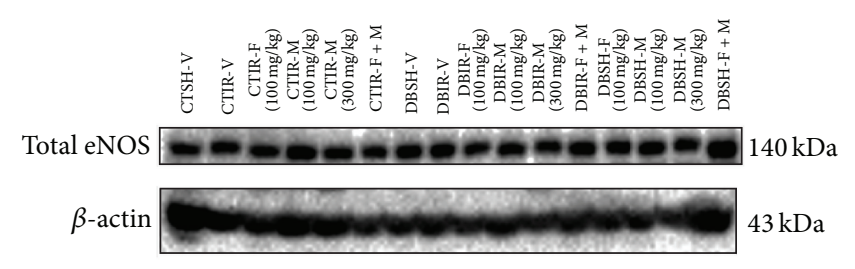

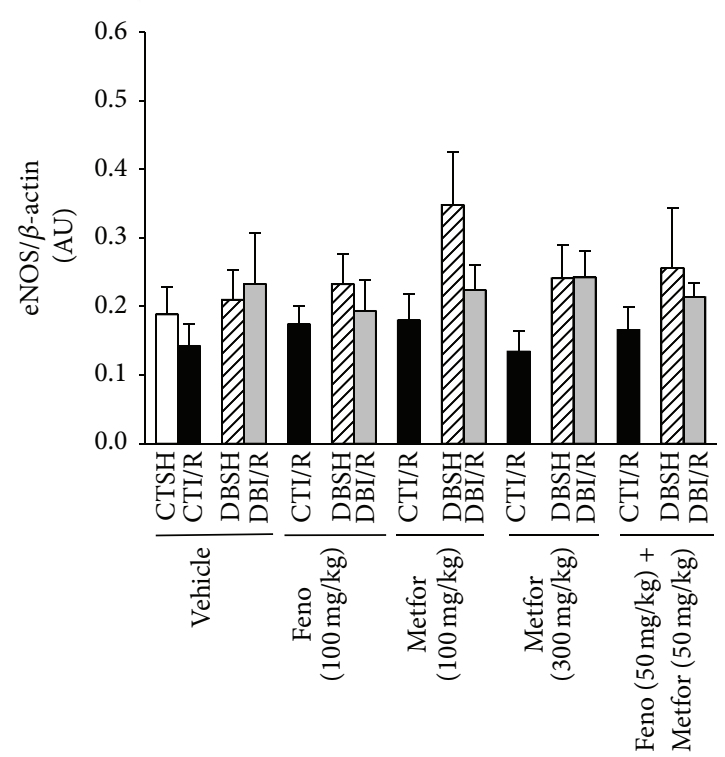

(a)

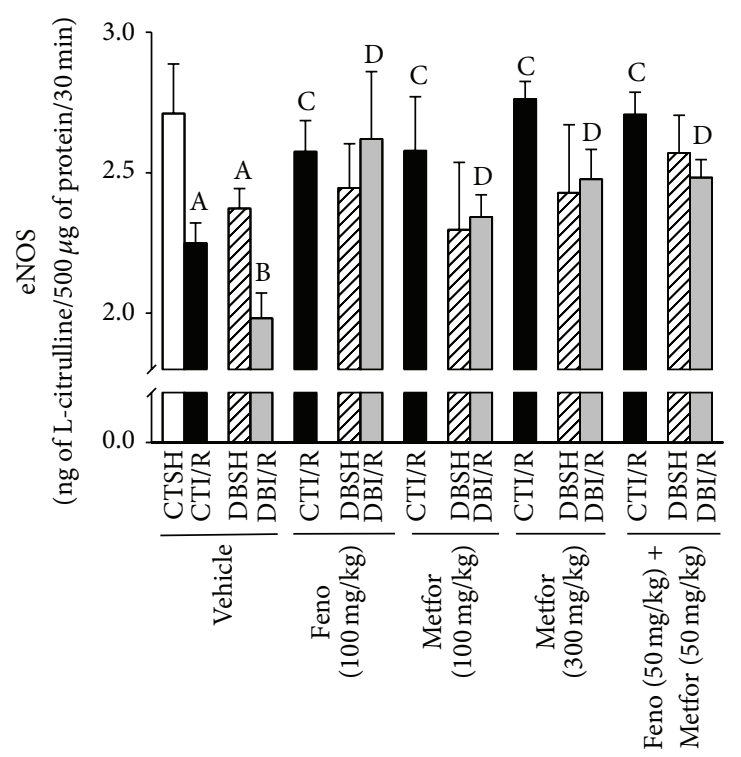

(c)

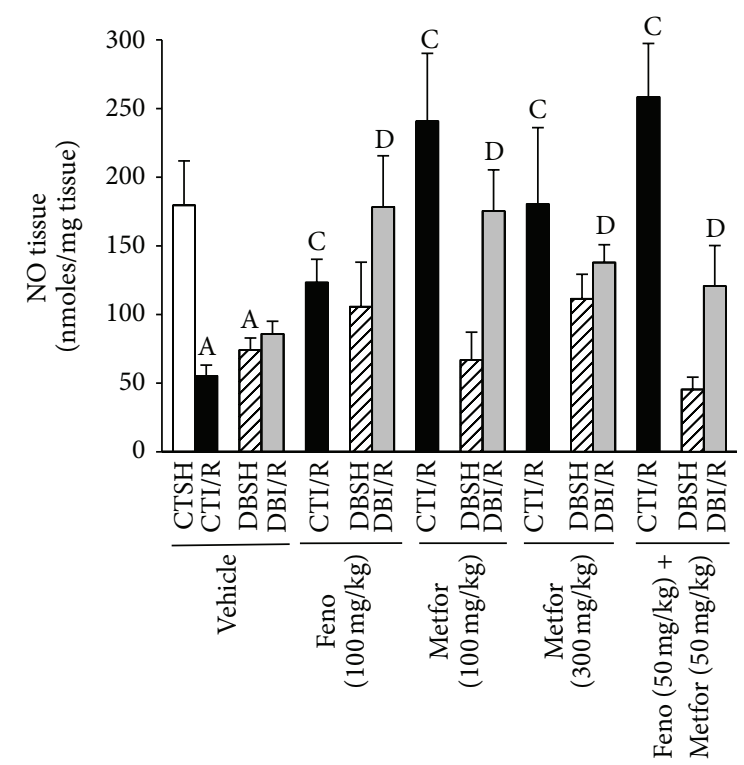

(b)

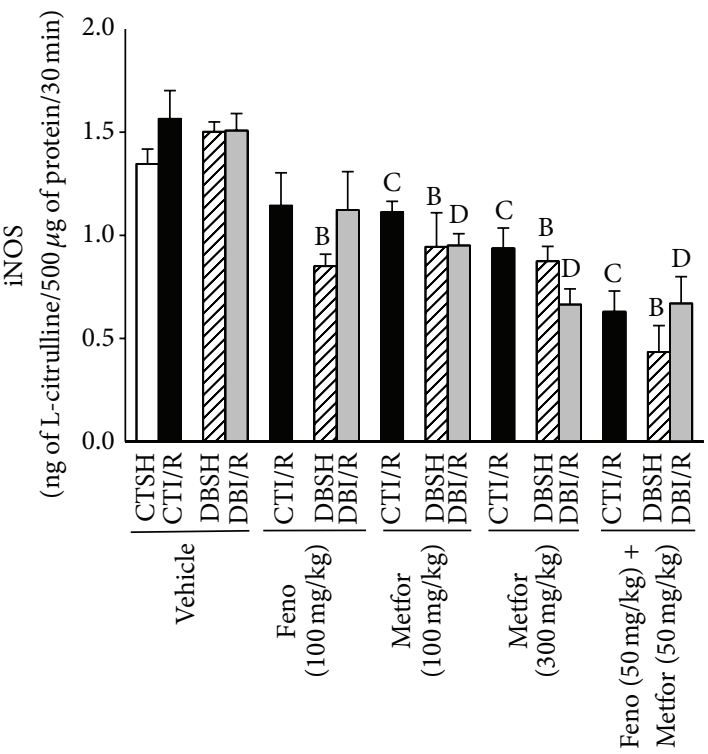

(d)

FIGURE 9: Effect of fenofibrate, metformin, and their combination on nitric oxide system. (a) The expression of endothelial nitric oxide synthase (eNOS) was analyzed by Western blot in the left ventricle of control- (CT-) and diabetic- (DB-) rats, subjected to sham (SH) or ischemia/reperfusion (I/R) injury, receiving 14 days of either vehicle, fenofibrate (F or Feno, $100 \mathrm{mg} / \mathrm{kg}$ ), metformin (M or Metfor, 100 or $300 \mathrm{mg} / \mathrm{kg}$ ), or Feno $(50 \mathrm{mg} / \mathrm{kg})+$ Metfor $(50 \mathrm{mg} / \mathrm{kg}$ ) and (b) tissue NO production and the activity of (c) eNOS and (d) iNOS. The bars represent the mean \pm SEM of $4-6$ different experiments. ${ }^{\mathrm{A}} P<0.05$ versus CTSH-Vehicle, ${ }^{\mathrm{B}} \mathrm{P}<0.05$ versus DBSH-Vehicle, ${ }^{\mathrm{C}} P<0.05$ versus CTI/R-Vehicle, and ${ }^{\mathrm{D}} P<0.05$ versus DBI/R-Vehicle two-way ANOVA followed by Duncan's post hoc test. 
atherosclerosis) and it is a rational therapeutic target to restore NO-mediated endothelial function and reduce disease progression [39]. In our investigation, we observed that the $\mathrm{BH}_{4}: \mathrm{BH}_{2}$ ratio decreased in CTI/R and $\mathrm{DBI} / \mathrm{R}$ and that the treatment with agonists of $\operatorname{PPAR} \alpha$ (fenofibrate + metformin) promoted an increase in $\mathrm{BH}_{4}: \mathrm{BH}_{2}$ ratio under these conditions.

Biosynthesis of $\mathrm{BH}_{4}$ occurs mainly via de novo pathway [38]. The synthesis of $\mathrm{BH}_{4}$ by this pathway is initiated by the action of GTPCH-I, which is the rate-controlling enzyme. Cai et al. [40] demonstrated that the transfection of human aortic endothelial cells with GTPCH-I markedly augmented $\mathrm{BH}_{4}$ levels, increased total eNOS activity, increased the quantity of dimerised eNOS, and increased NO synthesis. Several studies have shown that diabetes reduces $\mathrm{BH}_{4}$ bioavailability by increasing $26 \mathrm{~S}$ proteasome-dependent degradation of GTPCH-I [41]. In contrast, cardiomyocyte-specific overexpression of the GTPCH-I gene restored the efficacy of ischemic preconditioning to reduce myocardial I/R injury during hyperglycemia by increasing bioavailability of $\mathrm{BH}_{4}$ and NO [42]. We measured the in vivo expression of GTPCHI and showed that, in I/R and DB conditions, the expression of the enzyme is decreased and the combined treatment promoted higher GTPCH-1 expression, further supporting Liu et al. [43] report showing that, in HUVECs, fenofibrate increased GTPCH-I expression in a concentration dependent manner.

At the clinical level, fenofibrate, metformin, and/or their combination have been used to treat lipid and glucose metabolic alterations [44], to study the effect on lymphocyte cytokine release in patients with early glucose metabolism abnormalities [45], and to explore the effect on coagulation and fibrinolysis in impaired glucose tolerance patients [46]. The widespread use in clinic and our data allowed us to suggest that the therapeutic effects produced by fenofibrate + metformin could exert a cardioprotector effect in T2D patients.

\section{Conclusions}

In our study we demonstrated that fenofibrate + metformin, at low doses, generates cardioprotection in a rat model of T2D and AMI most probably through PPAR $\alpha$ activation. These findings may represent a novel treatment strategy to limit I/R injury in patients with T2D.

\section{Competing Interests}

The authors declare that they have no competing interests.

\section{Acknowledgments}

The authors thank Miguel Ángel Rosas-Lezama and José Saúl Carreón Cervantes for the technical assistance. Víctor Hugo Oidor-Chan received a Ph.D. fellowship (232874) from CONACyT (Consejo Nacional de Ciencia y Tecnología, México). This work was supported by CONACyT Grant 222720 to Alicia Sánchez-Mendoza.

\section{References}

[1] R. A. DeFronzo, "Pharmacologic therapy for type 2 diabetes mellitus," Annals of Internal Medicine, vol. 131, no. 4, pp. 281303, 1999.

[2] S. P. Gray and K. Jandeleit-Dahm, "The pathobiology of diabetic vascular complications-cardiovascular and kidney disease," Journal of Molecular Medicine, vol. 92, no. 5, pp. 441-452, 2014.

[3] P.-Y. Zhang, "Cardiovascular disease in diabetes," European Review for Medical and Pharmacological Sciences, vol. 18, no. 15, pp. 2205-2214, 2014.

[4] M. Aragno, R. Mastrocola, C. Medana et al., "Oxidative stressdependent impairment of cardiac-specific transcription factors in experimental diabetes," Endocrinology, vol. 147, no. 12, pp. 5967-5974, 2006.

[5] R. B. Wichi, V. Farah, Y. Chen, M. C. Irigoyen, and M. Morris, "Deficiency in angiotensin ATla receptors prevents diabetesinduced hypertension," The American Journal of PhysiologyRegulatory Integrative and Comparative Physiology, vol. 292, no. 3, pp. R1184-R1189, 2007.

[6] H. Li and U. Förstermann, "Uncoupling of endothelial NO synthase in atherosclerosis and vascular disease," Current Opinion in Pharmacology, vol. 13, no. 2, pp. 161-167, 2013.

[7] A. A. Bulhak, C. Jung, C.-G. Östenson, J. O. Lundberg, P.-O. Sjöquist, and J. Pernow, "PPAR- $\alpha$ activation protects the type 2 diabetic myocardium against ischemia-reperfusion injury: involvement of the PI3-kinase/Akt and NO pathway," The American Journal of Physiology-Heart and Circulatory Physiology, vol. 296, no. 3, pp. H719-H727, 2009.

[8] C. Dumitrescu, R. Biondi, Y. Xia et al., "Myocardial ischemia results in tetrahydrobiopterin $(\mathrm{BH} 4)$ oxidation with impaired endothelial function ameliorated by BHIN4," Proceedings of the National Academy of Sciences of the United States of America, vol. 104, no. 38, pp. 15081-15086, 2007.

[9] U. Förstermann and W. C. Sessa, "Nitric oxide synthases: regulation and function," European Heart Journal, vol. 33, no. 7, pp. 829-837, 2012.

[10] A. Magenta, S. Greco, M. C. Capogrossi, C. Gaetano, and F. Martelli, "Nitric oxide, oxidative stress, and p66Shc interplay in diabetic endothelial dysfunction," BioMed Research International, vol. 2014, Article ID 193095, 16 pages, 2014.

[11] R. Eldor, R. A. DeFronzo, and M. Abdul-Ghani, "In vivo actions of peroxisome proliferator-activated receptors: glycemic control, insulin sensitivity, and insulin secretion," Diabetes Care, vol. 36, supplement 2, pp. S162-S174, 2013.

[12] P. R. Holden and J. D. Tugwood, "Peroxisome proliferatoractivated receptor alpha: role in rodent liver cancer and species differences," Journal of Molecular Endocrinology, vol. 22, no. 1, pp. 1-8, 1999.

[13] L. G. Cervantes-Pérez, M. D. Ibarra-Lara, B. Escalante et al., "Endothelial nitric oxide synthase impairment is restored by clofibrate treatment in an animal model of hypertension," European Journal of Pharmacology, vol. 685, no. 1-3, pp. 108$115,2012$.

[14] T.-L. Yue, W. Bao, B. M. Jucker et al., "Activation of peroxisome proliferator-activated receptor- $\alpha$ protects the heart from ischemia/reperfusion injury," Circulation, vol. 108, no. 19, pp. 2393-2399, 2003.

[15] N. S. Wayman, Y. Hattori, M. C. McDonald et al., "Ligands of the peroxisome proliferator-activated receptors (PPAR- $\gamma$ and PPAR- $\alpha$ ) reduce myocardial infarct size," The FASEB Journal, vol. 16, no. 9, pp. 1027-1040, 2002. 
[16] G. Barreto-Torres, R. Parodi-Rullán, and S. Javadov, “The role of PPAR $\alpha$ in metformin-induced attenuation of mitochondrial dysfunction in acute cardiac ischemia/reperfusion in rats," International Journal of Molecular Sciences, vol. 13, no. 12, pp. 7694-7709, 2012.

[17] L. Ibarra-Lara, E. Hong, E. Soria-Castro et al., "Clofibrate $\operatorname{PPAR} \alpha$ activation reduces oxidative stress and improves ultrastructure and ventricular hemodynamics in no-flow myocardial ischemia," Journal of Cardiovascular Pharmacology, vol. 60, no. 4, pp. 323-334, 2012.

[18] L. Flohé and F. Otting, "Superoxide dismutase assays," Methods in Enzymology, vol. 105, pp. 93-104, 1984.

[19] F. A. Tenorio and L. P. G. del Valle, "Validación de un método analítico espectrofotométrico para la cuantificación de metabolitos estables de óxido nítrico en fluidos biológicos Validation of a spectrophotometric analytical method for quantifying stable," Revista Mexicana de Ciencias Farmacéuticas, vol. 36, no. 1, pp. 31-41, 2005.

[20] Y. Hu, Y. Chen, L. Ding et al., "Pathogenic role of diabetesinduced PPAR- $\alpha$ down-regulation in microvascular dysfunction," Proceedings of the National Academy of Sciences of the United States of America, vol. 110, no. 38, pp. 15401-15406, 2013.

[21] S. Narravula and S. P. Colgan, "Hypoxia-inducible factor 1mediated inhibition of peroxisome proliferator-activated receptor $\alpha$ expression during hypoxia," Journal of Immunology, vol. 166, no. 12, pp. 7543-7548, 2001.

[22] V. Chavali, S. C. Tyagi, and P. K. Mishra, "Predictors and prevention of diabetic cardiomyopathy," Diabetes, Metabolic Syndrome and Obesity: Targets and Therapy, vol. 6, pp. 151-160, 2013.

[23] S. W. Schaffer, B. H. Tan, and G. L. Wilson, "Development of a cardiomyopathy in a model of noninsulin-dependent diabetes," The American Journal of Physiology, vol. 248, no. 2, pp. H179H185, 1985.

[24] D. Aronson, A. Musallam, J. Lessick et al., "Impact of diastolic dysfunction on the development of heart failure in diabetic patients after acute myocardial infarction," Circulation: Heart Failure, vol. 3, no. 1, pp. 125-131, 2010.

[25] M. Guerre-Millo, P. Gervois, E. Raspé et al., "Peroxisome proliferator-activated receptor $\alpha$ activators improve insulin sensitivity and reduce adiposity," The Journal of Biological Chemistry, vol. 275, no. 22, pp. 16638-16642, 2000.

[26] J. Rieusset, M. Roques, K. Bouzakri, E. Chevillotte, and H. Vidal, "Regulation of $\mathrm{p} 85 \alpha$ phosphatidylinositol-3-kinase expression by peroxisome proliferator-activated receptors (PPARs) in human muscle cells," FEBS Letters, vol. 502, no. 3, pp. 98-102, 2001.

[27] I. Pavo, G. Jermendy, T. T. Varkonyi et al., "Effect of pioglitazone compared with metformin on glycemic control and indicators of insulin sensitivity in recently diagnosed patients with type 2 diabetes," Journal of Clinical Endocrinology and Metabolism, vol. 88, no. 4, pp. 1637-1645, 2003.

[28] T. Ogata, T. Miyauchi, S. Sakai, M. Takanashi, Y. IrukayamaTomobe, and I. Yamaguchi, "Myocardial fibrosis and diastolic dysfunction in deoxycorticosterone acetate-salt hypertensive rats is ameliorated by the peroxisome proliferator-activated receptor-alpha activator fenofibrate, partly by suppressing inflammatory responses associated with the nuclear factorkappa-B pathway," Journal of the American College of Cardiology, vol. 43, no. 8, pp. 1481-1488, 2004.
[29] S. Ichihara, K. Obata, Y. Yamada et al., "Attenuation of cardiac dysfunction by a PPAR- $\alpha$ agonist is associated with downregulation of redox-regulated transcription factors," Journal of Molecular and Cellular Cardiology, vol. 41, no. 2, pp. 318-329, 2006.

[30] T. Ogata, T. Miyauchi, S. Sakai, Y. Irukayama-Tomobe, K. Goto, and I. Yamaguchi, "Stimulation of peroxisome-proliferatoractivated receptor alpha (PPAR alpha) attenuates cardiac fibrosis and endothelin-1 production in pressure-overloaded rat hearts," Clinical Science, vol. 103, supplement, pp. 284S-288S, 2002.

[31] M. Rose, P. Balakumar, and M. Singh, "Ameliorative effect of combination of fenofibrate and rosiglitazone in pressure overload-induced cardiac hypertrophy in rats," Pharmacology, vol. 80, no. 2-3, pp. 177-184, 2007.

[32] T. Li, Q. Zhang, J. Zhang et al., "Fenofibrate induces apoptosis of triple-negative breast cancer cells via activation of NF- $\kappa \mathrm{B}$ pathway," BMC Cancer, vol. 14, article 96, 2014.

[33] G. S. Bhamra, D. J. Hausenloy, S. M. Davidson et al., "Metformin protects the ischemic heart by the Akt-mediated inhibition of mitochondrial permeability transition pore opening," Basic Research in Cardiology, vol. 103, no. 3, pp. 274-284, 2008.

[34] J. W. Calvert, S. Gundewar, S. Jha et al., "Acute metformin therapy confers cardioprotection against myocardial infarction via AMPK-eNOS- mediated signaling," Diabetes, vol. 57, no. 3, pp. 696-705, 2008.

[35] M. Paiva, N. P. Riksen, S. M. Davidson et al., "Metformin prevents myocardial reperfusion injury by activating the adenosine receptor," Journal of Cardiovascular Pharmacology, vol. 53, no. 5, pp. 373-378, 2009.

[36] A. A. Bulhak, P.-O. Sjöquist, C.-B. Xu, L. Edvinsson, and J. Pernow, "Protection against myocardial ischaemia/reperfusion injury by PPAR- $\alpha$ activation is related to production of nitric oxide and endothelin-1," Basic Research in Cardiology, vol. 101, no. 3, pp. 244-252, 2006.

[37] S. P. Jones, J. J. M. Greer, A. K. Kakkar et al., "Endothelial nitric oxide synthase overexpression attenuates myocardial reperfusion injury," American Journal of Physiology-Heart and Circulatory Physiology, vol. 286, no. 1, pp. H276-H282, 2004.

[38] A. Rubio-Guerra, "Is tetrahydrobiopterin a therapeutic option in diabetic hypertensive patients?" Integrated Blood Pressure Control, vol. 2010, no. 3, pp. 125-132, 2010.

[39] N. J. Alp, M. A. McAteer, J. Khoo, R. P. Choudhury, and K. M. Channon, "Increased endothelial tetrahydrobiopterin synthesis by targeted transgenic GTP-cyclohydrolase I overexpression reduces endothelial dysfunction and atheroscleroses in ApoEknockout mice," Arteriosclerosis, Thrombosis, and Vascular Biology, vol. 24, no. 3, pp. 445-450, 2004.

[40] S. Cai, N. J. Alp, D. McDonald et al., "GTP cyclohydrolase I gene transfer augments intracellular tetrahydrobiopterin in human endothelial cells: effects on nitric oxide synthase activity, protein levels and dimerisation," Cardiovascular Research, vol. 55, no. 4, pp. 838-849, 2002.

[41] S. Wang, J. Xu, P. Song, B. Viollet, and M.-H. Zou, "In vivo activation of AMP-activated protein kinase attenuates diabetesenhanced degradation of GTP cyclohydrolase I," Diabetes, vol. 58, no. 8, pp. 1893-1901, 2009.

[42] Z.-D. Ge, I. A. Ionova, N. Vladic et al., "Cardiac-specific overexpression of GTP cyclohydrolase 1 restores ischaemic preconditioning during hyperglycaemia," Cardiovascular Research, vol. 91, no. 2, pp. 340-349, 2011. 
[43] J. Liu, C. Lu, F. Li et al., "PPAR-agonist fenofibrate upregulates tetrahydrobiopterin level through increasing the expression of Guanosine $5^{\prime}$-triphosphate cyclohydrolase-I in human umbilical vein endothelial cells," PPAR Research, vol. 2011, Article ID 523520, 8 pages, 2011.

[44] M. Nieuwdorp, E. S. G. Stroes, and J. J. P. Kastelein, "Normalization of metabolic syndrome using fenofibrate, metformin or their combination," Diabetes, Obesity and Metabolism, vol. 9, no. 6, pp. 869-878, 2007.

[45] R. Krysiak, A. Gdula-Dymek, and B. Okopien, "Lymphocytesuppressing, endothelial-protective and systemic anti-inflammatory effects of metformin in fenofibrate-treated patients with impaired glucose tolerance," Pharmacological Reports, vol. 65, no. 2, pp. 429-434, 2013.

[46] R. Krysiak, A. Gdula-Dymek, and B. Okopień, "Effect of metformin on selected parameters of hemostasis in fenofibratetreated patients with impaired glucose tolerance," Pharmacological Reports, vol. 65, no. 1, pp. 208-213, 2013. 


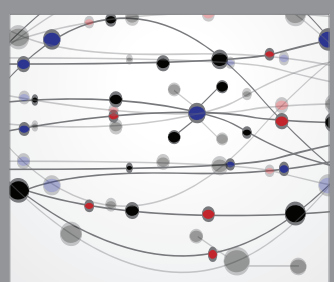

The Scientific World Journal
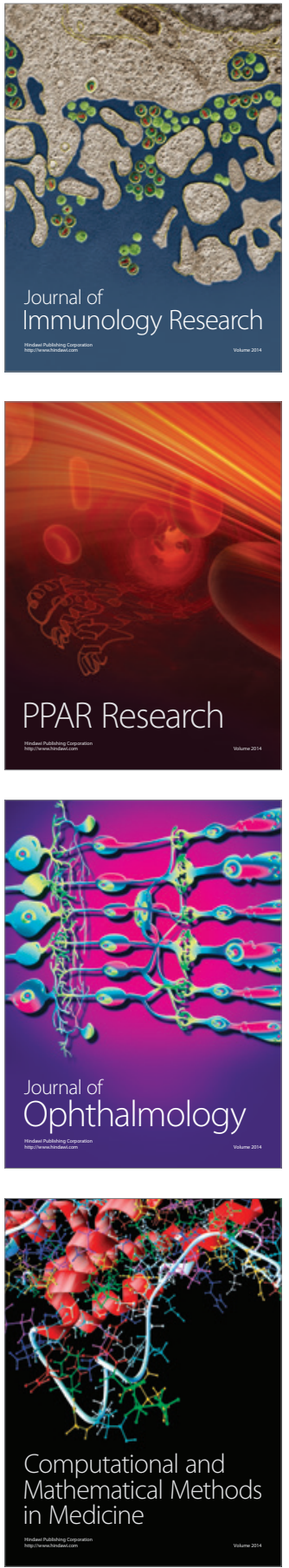

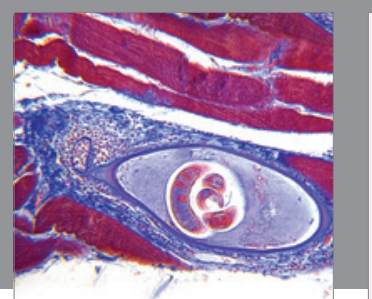

Gastroenterology Research and Practice

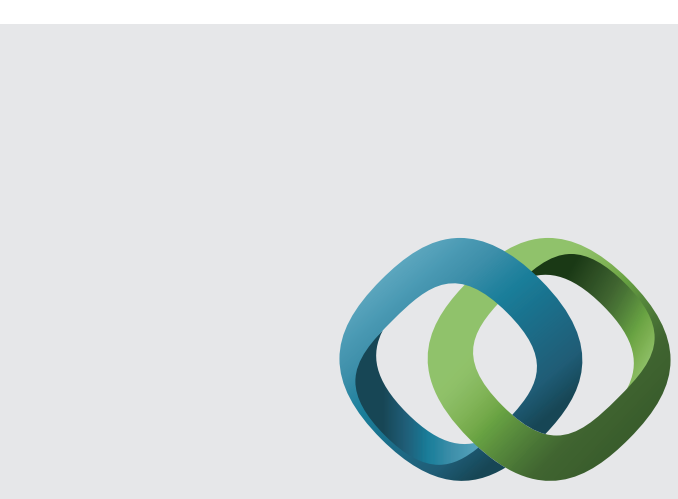

\section{Hindawi}

Submit your manuscripts at

http://www.hindawi.com
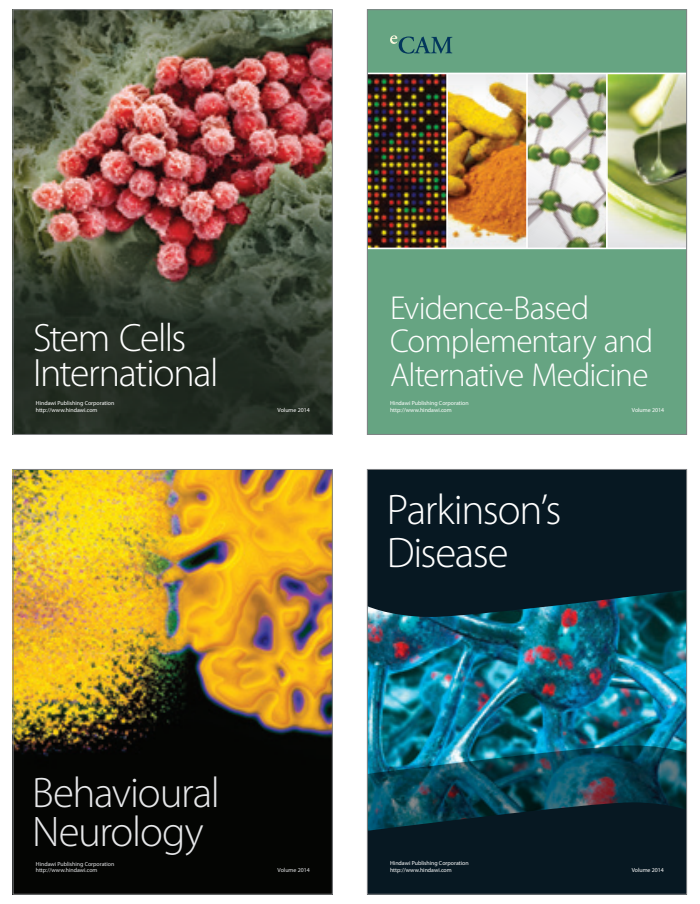
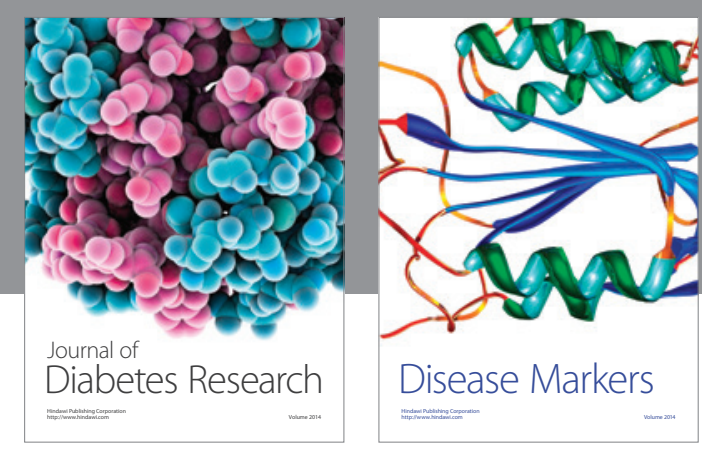

Disease Markers
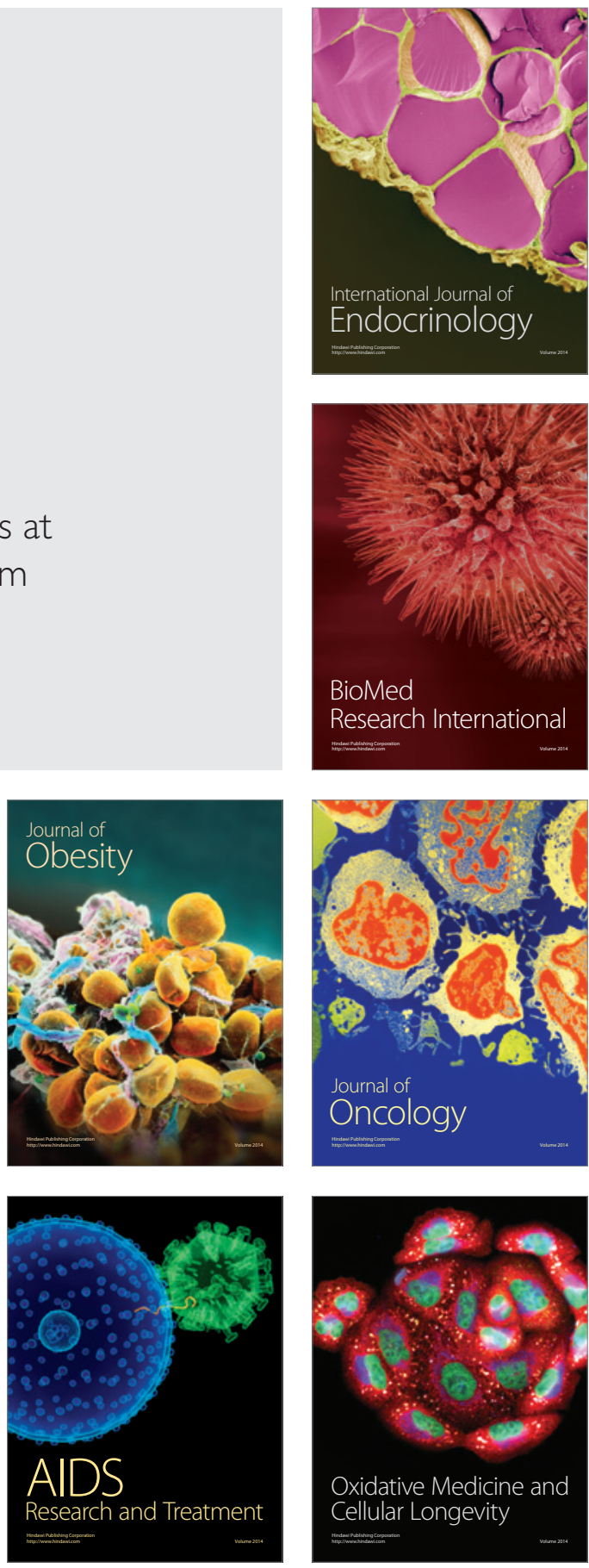